San Jose State University

SJSU ScholarWorks

Master's Theses

Master's Theses and Graduate Research

1994

\title{
Three analytical approaches to Utopias with implications for all proposals of systemic reform
}

Christopher Patrick Harget

San Jose State University

Follow this and additional works at: https://scholarworks.sjsu.edu/etd_theses

\section{Recommended Citation}

Harget, Christopher Patrick, "Three analytical approaches to Utopias with implications for all proposals of systemic reform" (1994). Master's Theses. 913.

DOI: https://doi.org/10.31979/etd.ynjf-y8as

https://scholarworks.sjsu.edu/etd_theses/913

This Thesis is brought to you for free and open access by the Master's Theses and Graduate Research at SJSU ScholarWorks. It has been accepted for inclusion in Master's Theses by an authorized administrator of SJSU ScholarWorks. For more information, please contact scholarworks@sjsu.edu. 


\section{INFORMATION TO USERS}

This manuscript has been reproduced from the microfilm master. UMI films the text directly from the original or copy submitted. Thus, some thesis and dissertation copies are in typewriter face, while others may be from any type of computer printer.

The quality of this reproduction is dependent upon the quality of the copy submitted. Broken or indistinct print, colored or poor quality illustrations and photographs, print bleedthrough, substandard margins, and improper alignment can adversely affect reproduction.

In the unlikely event that the author did not send UMI a complete manuscript and there are missing pages, these will be noted. Also, if unauthorized copyright material had to be removed, a note will indicate the deletion.

Oversize materials (e.g., maps, drawings, charts) are reproduced by sectioning the original, beginning at the upper left-hand corner and contimuing from left to right in equal sections with small overlaps. Each original is also photographed in one exposure and is included in reduced form at the back of the book.

Photographs included in the original manuscript have been reproduced xerographically in this copy. Higher quality $6^{n} \times 9^{n}$ black and white photographic prints are available for any photographs or illustrations appearing in this copy for an additional charge. Contact UMI directly to order.

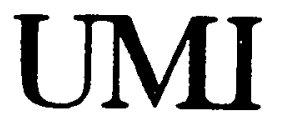

A Bell \& Howell information Company 


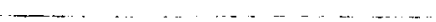


THREE ANALYTICAL APPROACHES TO UTOPIAS

WITH IMPLICATIONS FOR ALL PROPOSALS OF SYSTEMIC REFORM

\author{
A Thesis \\ Presented to \\ The Faculty of the Department of Political Science \\ San Jose State University
}

\author{
In Partial Fulfillment \\ of the Requirements for the Degree \\ Master of Arts
}

by

Christopher Patrick Harget

December 1994 
UMI Number: 1361171

Copyright 1994 by Harget, Christopher Patrick

All rights reserved.

UMI Microform Edition 1361171

Copyright 1995, by UMI Company. All rights reserved.

This microform edition is protected against unauthorized copying under Title 17, United States Code.

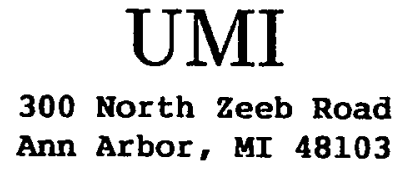


Copyright 1994

Christopher Patrick Harget

ALL RIGHTS RESERVED 
APPROVED FOR THE DEPARTMENT OF POLITICAL SCIENCE

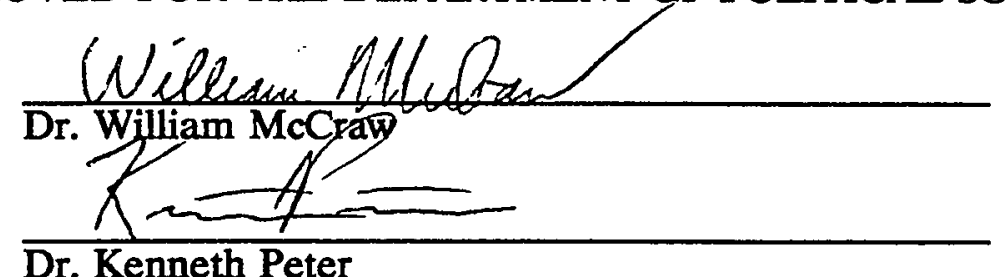

Dr. Kenneth Peter

Bieve Sumer

Dr. Billie Jensen

APPROVED FOR THE UNIVERSITY

73. Low Lewandoweh 


\section{ABSTRACT \\ THREE ANALYTICAL APPROACHES TO UTOPIAS WITH IMPLICATIONS FOR ALL PROPOSALS OF SYSTEMIC REFORM}

by Christopher Patrick Harget

This thesis addresses the topic of systematically analyzing proposals of systemic reform for viability. Three approaches are developed and demonstrated on Utopian proposals by Tommaso Campanella (City of the Sun), F.M.C. Fourier (works on Fourierism), Edward Bellamy (Looking Backwards 2000-1887) and H.G. Wells (A Modern Utopia). Testing systemic reform proposals by abnegation compares them to a check list of categoric flaws. Testing plans by affirmation assesses how successfully systems pursue seven factors which enhance viability and optimize social contentment-resource efficiency, proportionality of benefit distribution, positive pressure to create resources, positive pressure to create social goods, accurate aggregation of individual desires, enactment of highest value benefits, appropriate limits of the system. Testing plans on an ad hoc basis identifies any outstanding traits and their likely negative or positive effects on systemic viability. Conclusions about the advantages and disadvantages of each approach are given, with recommendations for their usage and for future directions of research. 


\section{Acknowledgments}

My Wife,

My Mom,

My Boys,

My Friends,

Hope, determination, and worlds yet to be. 
Table of Contents

Preface $\ldots \ldots \ldots \ldots \ldots \ldots \ldots \ldots \ldots \ldots \ldots \ldots \ldots \ldots \ldots \ldots \ldots$ vii

Chapter $1 \quad$ Introduction $\ldots \ldots \ldots \ldots \ldots \ldots \ldots \ldots \ldots$

Chapter $2 \quad$ Importance of social systems $\ldots \ldots \ldots \ldots$

Chapter $3 \quad$ Empirical social systems $\ldots \ldots \ldots \ldots \ldots \ldots \ldots$

Chapter $4 \quad$ Utopia, opportunities and challenges . . . . . . . . 14

Chapter $5 \quad$ Individual versus collective $\ldots \ldots \ldots \ldots \ldots \ldots \ldots \ldots$

Chapter $6 \quad$ Testing by Abnegation $\ldots \ldots \ldots \ldots \ldots \ldots$

Chapter $7 \quad$ Testing by Affirmation $\ldots \ldots \ldots \ldots \ldots \ldots$

Chapter $8 \quad$ Testing by ad hoc analysis $\ldots \ldots \ldots \ldots \ldots$

Chapter $9 \quad$ Criteria for selecting case studies $\ldots \ldots \ldots \ldots \ldots$

Chapter $10 \quad$ Campanella's City of the Sun $\ldots \ldots \ldots \ldots$

Chapter $11 \quad$ Fourier's Phallansteries $\ldots \ldots \ldots \ldots \ldots \ldots \ldots$

Chapter $12 \quad$ Bellamy's backward look ............. 84

Chapter $13 \quad$ Well's Modern Utopia . . . . . . . . . . . . . . 94

Chapter $14 \quad$ Conclusions about Utopias $\ldots \ldots \ldots \ldots \ldots$

Chapter $15 \quad$ Recommendations for Reform proposals . . . . . . . 110

Chapter $16 \quad$ Conclusions about three tests $\ldots \ldots \ldots \ldots \ldots \ldots$

Bibliography . . . . . . . . . . . . . . . . . . . 123 


\section{Preface}

Confirming the suspicion that utopias would have problems in practical application is nothing revolutionary. What I wondered was 'why'? Why did the earnest produce of the intellects of so many mental giants fall short? The task I initially set for myself in the following work was to describe meaningfully the particular kinds of mistakes to which utopian proposals are prone. As the research proceeded, it became apparent that to understand why a social system would fail, it was first necessary to understand why a social system would succeed. If both could be understood, then insight into how to make a 'sick' social system healthier could be gained. In this pursuit, I did a great deal of pondering. Many large sections of this thesis are entirely original.

Since reform involves planning, and utopias are plans on a grand scale, it is my hope that the large problems of various utopias can be generalized to give insight into improving the success of social system reform plans at any scale. Successfully transferring the metaphor in this direction may perhaps be revolutionary.

The goal of earnest utopian proposals is perfect social contentment. Whatever the specifics of the particular plan may be, its object is to remove all valid complaints about society from the citizens' lips. The world has changed much since Plato's

Republic was first penned; the existence of discontent, less so.

The goal of pragmatic systemic reform proposals is to improve social vii 
contentment for a reasonable amount of time. Since aggregate contentment is rather fluid, marginal gain in one realm may result in a net reduction overall. Obtaining an awareness of this phenomenon is critical to the successful steering and adapting of social systems. Families, communities, governments and societies all face this reality frequently in their policy making.

The goal of the this thesis is to clarify the process of and describe analytical tools for assessing the viability of proposals for systemic reform which aim at improving social contentment. 


\section{Chapter 1}

Social systems are everywhere. Whether their design is in our DNA, our cultural memory, a dreamer's dream or some combination of all of these, they exist at all levels of society. They have existed since the earliest clans, and are imagined in the future in our most speculative fiction. Current systems have often developed by trial and error and are sometimes very robust. On other occasions, social systems are created from nothing by the stroke of a legislative pen. Utopian writers urge their better-mousetrap systems upon the world for the edification of the intelligentsia and the common individual alike. How to determine which proposed systems are favorable is therefore an ongoing concern.

Many particular social systems have fallen by the wayside of history and are not expected to return. Feudalism, slavery and federations of city-states may have gone the way of the Dodo, yet pieces of them may return with changing times. It is also conceivable that today's most advantageous social systems will at some later date be obsolete. Perhaps worse still, they may limp slowly into third-class status with their practitioners never aware of why life became so hard.

It is with the keen awareness that change forces us to reinvent ourselves and our world that this thesis is proposed and executed. To gain an understanding of what makes a social system more and less viable, we will examine in the following chapters extremes of viability as presented by two empirical social systems that have endured for more than a century and four utopian social systems that have never truly existed. In preparation for 
this survey, an overview of the methods and pitfalls of utopian proposals will be examined.

\section{Thesis}

Simply stated, many utopists and other reformers have an incomplete understanding of what makes a successful social system function. This is significant because this results in useless utopian proposals and the implementation of ineffective or frustrating reforms. Simply stated, the solution requires that to be successful, reformers should understand the necessary conditions for a viable and sustainable social system and recognize the factors that must be optimized in order to best achieve that condition. Three analytical approaches will be developed and demonstrated to validate this thesis: assessing reform proposals by abnegation, affirmation, and ad hoc analysis.

Simply stated, the advantages of this should be faster and more meaningful assessments of social system reform proposals. Also, the relative benefits of diverse systems may be more easily compared. This will facilitate reforms more likely to yield net social improvements and happy citizens. Further, insight in how to repair existing systems may be gained more easily in the light the criteria established to validate this thesis.

\section{Identifying Successful Social Systems}

In order to be desirable and sustainable, social systems must have actors and administrators whose self interests are served by contributing the necessary resources to 
each other for the system to produce a proportionately valuable and desired common good. Self interests may be fulfilled in emotional as well as material currencies.

Theoretical social systems (proposed reforms) can be tested by abnegation (i.e., compared against a list of classic failings) and deemed improbable if they possess several categories of significant flaws common to reform proposals. The list of these categories constitutes a swift litmus test.

Theoretical social systems (proposed reforms) can be tested by affirmation. Testing by affirmation is done by establishing whenever the necessary elements and pursuits of a viable social system are reasonably accounted for in a system's design. This method requires greater comprehension of the proposal in question as well as of the pertinent participants, and is most useful when determining whether to optimize or abandon a marginal reform proposal.

In Chapter Two we examine the importance of social systems, as well as the functioning of social systems, and define their parts. In Chapter Three we give a cursory examination of the advantages and disadvantages of some current systems, thus of what may be remedied or risked by engaging in reform. In Chapter Four we lay out the broad tendencies of utopians in their pursuit of perfection and separate tendencies not germane to "non-perfect" reform. Chapter Five examines the duality between centralized decisions and individual decisions. In Chapter Six, we list and give examples of the categories of common flaws to which reform proposals are prone. Chapter Seven puts forth a detailed description of the necessary conditions and pursuits for a viable social 
system. In Chapter Eight we describe the use of ad hoc analysis in assessing reform proposals. Chapter Nine describes the criteria by which the case utopias were selected. Chapters Ten through Thirteen examine utopian works by Campanella, Fourier, Bellamy and Wells to illustrate particular proposals and the challenges of analyzing them. In Chapter Fourteen we summarize lessons learned about measuring utopias in terms of system performance and about utopian proposals in general. Chapter Fifteen reviews and makes recommendations for the elements highly optimized systems tend to incorporate.

Finally, in Chapter Sixteen, we review what is learned about our three analytical tools, describe their advantages and disadvantages, and make recommendations for their use. In conclusion, a short hybrid approach is offered for use as an effective starting point for analysis of social systems. 


\section{Chapter Two}

This chapter seeks to illustrate the importance and function of social systems and to define their elements.

\section{The Effect of Social Systems}

Social Systems are the formal structures through which we interact. They allow civilization, fellowship and the advancement of knowledge. They enhance the quality of existence for their members. Typically, they act as a safeguard of lesser members and facilitate the prevention of injustice.

They are also frequently flawed. Social systems can be, and often are, abused by their powerful members. Often social systems are slow to respond to changing trends. On some matters a given social system may never respond. This is most common if the matter only has pertinence to a disenfranchised element.

Social systems are often far removed from the problems they are set up to address. Hence, they can easily be inefficient, inconsistent in effectiveness, or consistently ineffective. When guidelines are poorly conceived, social systems can stimulate counterproductive behavior.

When the population is not uniform, social systems' guidelines can be restrictive and repressive. Often, they consume resources before any other parties and hence may impede other forms of progress. 


\section{What is a Social System?}

A social system is an agreement of behavior and expenditure designed to increase benefit to its participants. The system increases total benefit to the participants by stimulating and or restraining behaviors within the group. Its participants are selfdirected actors with resources and allegiance to offer the system. Actors aggregate into cleavages to pursue similar desires. Cleavages compete for the specific articulation of aggregated desires, and hence expenditures, by the system. Some actors operate as system administrators. These elites interpret and evaluate aggregate desires to manifest some desires via the social system. Elites receive their status from actors (usually via their cleavages). Actors vote with their allegiance, their resources, and their feet.

A successful social system perpetuates itself by enhancing social contentment. This is because enhancing support for the system on the margin is achieved by enhancing social contentment on the margin. Ultimately, motive force comes from the desires of the people in the system. If a desire is flagrantly neglected, the system will cease to have the motive force of that desire (because those people will cease to contribute in hopes of having that desire fulfilled).

Social systems must contain the following elements: actors, resources and communication. The necessary condition for a social system to be sustainable is that actors perceive sufficient comparative benefit to agree to continue supporting the system (if actors saw comparative benefit in external systems they would tend to go leave). This 
is enhanced by actors' commitment to, and faith in, the social system. Typically this commitment contains both subjective and rational components.

\section{Definitions of Terms:}

The following are terms that will be used with specific intent throughout this thesis. They are working definitions that seem appropriate to describing social system structures alone.

Desirable: having the perception of being equal to or better than alternative available social systems. "Better" is gauged by the actors within an existing or proposed social system, in terms of how well it satisfies their pertinent needs, how much it costs, and how little it interferes with pursuit of their other priorities.

Sustainable: the soundness of a system to provide the common good expected of it, and continue doing so. This robustness is affected by the system's ability to minimize the ill effects of change, corruption, incomplete participation, imperfect execution and other problems.

Actors: self-directed individuals who constitute the population of the social system. These participants are the raison d'etre of a social system. They each determine the success of the social system in fulfilling their needs.

Costs: that which is necessarily lost in receiving the benefits of the social system. Three categories are: 1.) resources (e.g., taxes), 2.) behaviors prohibited (e.g., driving on 
the left side of the road), 3.) opportunity costs (e.g, supposedly, actors can not simultaneously have guns and butter [or guns, butter, and balanced budgets]).

Cleavages: divisions in the general pool of actors, which separate those likely to behave in different ways on a specific issue. Actors typically are in many cleavages, each defined by a different issue.

Benefits (of the system): the good that actors perceive they receive from the system. These may manifest themselves as order, quality of life, peace, safety, security, predictability, belongingness, increased opportunity, status, and/or material gain.

Competition: cleavages (or their designees) attempt to receive their specific desires ahead of or in place of other cleavages by convincing system administrators to fulfill those desires. Typically cleavages argue it is best, necessary, just or that their continuing status as administrator depends upon it. Competition is typically how desires are prioritized.

Restraints: guidelines, proscriptions, conventions and laws concerning behavior imposed by consensus or system administrators intended to increase total benefit through uniformity of action, prohibition of destructive acts and/or compulsion of proactively advantageous acts (e.g., drive on the right side of the road; don't shoot people; insure your car and yourself against collision and liability damage).

System administrators: actors who primarily facilitate the functioning of the system. They typically have some discretion over which goods the system creates. Their needs are met in part by their role of manifesting social goods via the system. 
Systemic reform: modifying an organizational structure such that the elements within the system consistently behave in a different manner.

Testing by abnegation: examining a social system--proposed or otherwise--for the presence of serious common flaws which may limit the potential success of the system, or make it untenable from its inception. If a preponderance of flaws are found the system may be rejected (i.e., abnegated).

Testing by affirmation: examining a social system--proposed or otherwise--for the presence of specific factors which contribute positively to the system's capacity to successfully enhance social contentment. If most factors are accounted for in a relatively effective way, the system may be accepted (i.e., affirmed). 


\section{Chapter Three}

This chapter provides examples of the complexities of reform considerations through empirical examples of social systems. This also demonstrates the significance of the problem addressed by the theoretical instrumentation developed in later chapters.

Given that systems often have drawbacks, one would expect reform to occur often. Considering the sheer number of levels and environments in which a social system can occur, perhaps they are reformed often. This is owing largely to the fluid nature of human relations and human wants. Large systems, however, change infrequently. Why this occurs is understandable enough. The outcome of systemic reform is unpredictable and can be a mixed blessing.

Proposals of reform have the potential to help. The Magna Carta was a reform of particular prominence, for it began a long series of reforms that gradually led to the democratization of a country. The United States Constitution was a reform, as were its amendments. These were significant in their establishment of the limits of temporal authority, and of obligations of the state to respect certain choices of its citizens. These are not, however, the only kind of outcomes for reform.

Proposals for reform have the potential to hurt, as well. The French Revolution bred the Terror. The Russian Revolution bred the purges. The Weimar Republic allowed the spread of fascism. The difference between deliverance and debacle is not always 
visible prima fascie and in advance. Thus it is no wonder that the United States Constitution has been amended only 26 times since 1789.

Even if there were no risks associated with change, high transition costs and inertia would discourage frivolous change. These, combined with limited information and the distraction of competing needs, helps to explain why imperfect social systems remain unreformed. Many current systems can clearly be found wanting.

The system by which medical care is provided has perceived drawbacks. At the present time, negatives cited in the media include the opinions that medical care in the United States is prohibitively expensive, bureaucratic, unevenly distributed and consumes a large percent of Gross Domestic Product. "Health care costs will grow from $14 \%$ of GDP to $19 \%$ even without an expansion of coverage to insure all Americans. ... Left unchecked, rising health costs will consume almost two-thirds of the increase in GDP for each American for the rest of the decade" (Task Force on National Health 3). This might seem unacceptable.

However, these perceived disadvantages are to some degree offset by a number of perceived advantages. They include the perception that medical care in the United States is abundantly available, very advanced and reasonably ethical. Should an advantage be sacrificed to diminish a disadvantage? It depends upon one's calculus.

Again in the United States, the system (or systems) by which secondary education is provided is another mixed story. Negatives cited include uneven quality, heavy challenges posed by diverse student populations, median achievement levels well below 
the global best and minimal preparation for professional life. This is counter balanced the tradeoffs. Positives cited include no direct monetary cost to users, universal availability, reduction in teenage unemployment, it socializes citizens and serves some segments of the population admirably. By what standard should acceptability be judged?

Contemporary capitalism illustrates advantages and disadvantages of an empirical economic social system. Capitalism may not exist in its pure theoretical form, but certainly does exist in some very tangible forms. This economic system has been accepted in various forms by various nations, but some disadvantages are almost always inherent: relative poverty for those least competitive, harmful externalities often carried by the population as a whole, and tragic individual cases of failure give capitalism in most places at the very least a bitter-sweet character. However its positives include the creation of great surpluses of wealth, individual accountability, consumption proportionate to production, liberty and the opportunity to achieve wealth. Consequently, there is much to be lost by inept reform. And yet, reform is proposed frequently. Decision-makers must weigh proposals almost as often as dissatisfied constituents communicate with them. Often these proposals may tamper with complex interrelated systemic structures.

Proposals are intended to redress deficiencies in the status quo social system. They purport to decrease crime, poverty, inequality, harm to the psyche, time lost, or the 
cost of the system. Inversely, they purport to increase affluence, quality of life, reliability, legitimacy, or security, to name a few.

Whatever a proposed systemic reform is intended to achieve, its actual effect could be negative. New systems could on the whole be worse than the old. They might include new disadvantages such instability, short-sightedness, repression, ineffectiveness in other spheres, lack of sustainability if grown, resistance to adaptation, openness to exploitation. Further, reforms might fall short of their prime target because of a misreading of the pertinent participants.

Given the potential risks and benefits of reform, it should not be entered into, at a high level, without lucid consideration. Given the likely complexities of reform, that consideration ought to be thorough and well balanced. Thus, the potential value of analytical tools in saving time and improving systemic reform is considerable. 


\section{Chapter Four}

This chapter begins the analysis of utopian trends and the opportunities they present for insight into the creation of reform proposals.

It will be recalled from Chapter One that "Simply stated, many utopists and other reformers have an incomplete understanding of what makes a successful social system function."

For the purposes of advancing techniques for analyzing systemic reform proposals, utopias provide significant opportunities. Utopias often attempt comprehensive reforms on the largest possible scale and often alter systems at many levels simultaneously. Utopian reforms are typically many degrees different from any prevailing status quo, and hence the changes proposed are revolutionary rather than evolutionary.

The risk of failure is high when making so many changes. Further, the failures are likely to be large and obvious. However, utopian proposals, even if they fail, offer valuable insights into how reform proposals also may fail. Since such failure is likely to be largescale, the study of it should be expedited as a result. If a utopia is likely to succeed, then there is much to be learned from what it actively does well. Either way, studies of utopias provide significant opportunities. 
Utopias present challenges as well. The reform plan is sometimes encased in a fictive narration. Devices of plot and character intrude. This may inhibit the author from laying out his or her plan clearly, and arguing for it thoroughly.

Moreover, utopias seldom isolate a single element for change. This can conceal the causal element when failure occurs. Without this isolation, determining causality may not be possible.

Utopian plans tend to assume abilities and devices unavailable to most status quo administrators. The sweeping temporal powers and inexhaustible persuasiveness required to enact some utopian plans make them prohibitive. This would be regardless of whatever economies or social equities the plans might provide. Such plans are more difficult to consider. Despite this, utopias can be well worth the challenge of analyzing them.

\section{What To Keep In Mind When Reading a Utopia}

Utopia, as it has come to be known, is a model polity aspiring to perfect community life. Lyman Tower Sargent cites more than 3200 utopian works in his bibliography, British and American Utopian Literature, 1516-1985 (499-558). These works have in common an idealized society as an integral part of their theme. And yet, these works are terrifically diverse. Certainly, they have not all been written for the same purpose. 
Doyne Dawson categorizes utopias into three varieties:

1. Folk utopias: myth, fantasy, messianic expectation.

2. Political utopianism: the "social," "realistic," "reconstructions" utopias of the philosophers. These have been of two kinds.

a) Classical utopianism: Plato and his imitators. The ideal society as a theoretical standard.

b) Modern utopianism: an adaptation of $2 a$. The ideal society as a program for political action. (5)

The utopias that have the most to offer in this study of systemic reform, are those which have a definite political--and typically economic and social as well--plan for action. The last two centuries have also seen hundreds of attempts by religious and secular communes to achieve a perfect community on earth. These proposals for a better socialpolitical-economic system have varied often in their details and occasionally in their macro-level organization.

These proposals have not, however, varied much in their tangible effect. The literature is relegated to scholars and the communes almost invariably fail in less than a generation. And yet, this vast body of theory and practice serves as a rich exposition of the flaws to which any proposal of systemic reform may be prone.

Utopias are not all without palpable effect. Some utopias do capture the popular imagination, give shape to the political ideals of would-be reformers, and act as critiques of the relevant status quo. These effects have been felt at the highest echelons of society. Occasionally utopists earn the ire of political elites for esteeming the status quo as 
wretched in comparison with a utopian plan. Since antiquity, Dawson note, elites have thought this hardly fair:

Nor is it right to bring Plato's Republic into discussion [of the best constitution] ... any attempt to judge it against the Spartan or Roman or Carthaginian constitution would be like putting forth some statue and comparing it with living and breathing men.--Polybius 6.47,trans. Mortimer Chambers. (223)

There can be found statues of people with eight arms, one-hundred-ten inch bust lines, or holding a torch over one-hundred feet in the air. These, too, should not be compared strenuously to 'living and breathing' people. Much creative license is available in utopian works, which can diffuse their commentaries. Also some amount of political chaos may occur when the incumbent system is compared to a system beyond its temporal and physical limits. Hence perspective is necessary to balance the value of the exercise versus the attendant distraction.

In the interest of progress, a proposed utopia should not be totally ignored, for it may have apprehended a valuable piece of truth. And yet, it may be so abstracted as to entirely disconnected from truth. The question arises then of how best to learn about all systemic reform proposals through the evaluation of utopias.

The answer proposed here is to correct for the biases and excesses unique to utopian reform proposals, and determine what characteristics remain for the comparison and evaluation of all proposals for systemic reform. Preparing for this by evaluating utopias requires three additional steps. The first is to describe the unique lapses of utopian construction. The second is to describe the unique lapses attributable to utopian 
writers' motivations. The third step is to proscribe admonitions to the reader of proposed utopias.

\section{Describing Utopia}

Utopias are a distinct category of writing. According to Glen Negley and J. Max Patrick:

There are three characteristics which distinguish the utopia from other forms of literature or speculations:

1. It is fictional

2. It describes a particular state or community.

3. Its theme is the political structure of that fictional state or community. (3)

While the thrust of some utopian writings is to moralize and criticize, many others straightforwardly advocate literal system designs. The assertion of these utopists is that their construction, if manifested, would constitute the perfect state or community. That sums up the apparent intent of such utopists, to achieve a modest improvement on God's creation.

Some theorists generalize weaknesses in what a typical utopia depends upon structurally. Any work of speculation requires assumptions, but utopists seem prone to rely on several very convenient, but hardly probable, assumptions. Ralf Dahrendorf suggests that typical utopias have five questionable structural requisites:

First, utopias do not grow out of familiar reality following realistic patterns of development. ... A second structural characteristic of utopias seems to be the uniformity of such societies or, to use more technical language, the existence of universal consensus on prevailing values and institutional arrangements. ... Universal consensus means the absence of structurally generated confiict. . . third, 
social harmony seems to be one of the factors adduced to account for utopian stability. . . fourth point, all processes going on in utopian societies follow recurrent patterns and occur within, and as part of, the design of the whole. Not only do they not upset the status quo: they affirm and sustain it. ... Finally, to add a more obvious observation, utopias generally seem to be curiously isolated from all other communities (if such are indeed assumed to exist at all). (107-110)

So it appears that utopists 'assume' harmonious dutiful citizens, who waste no energy contesting each other or the administrators of the social system. This allows utopists to concentrate on what they prefer: the system.

Utopists' structures seek to deal with what is easiest to manipulate: the system's rules. In so doing, they modify what is most believably modifiable. This leads to overworking one piece of the system, and letting another drift. As Thomas Molnar has said:

Utopianism's historical motivation was noted in our examination of the cyclical theory of history. Obviously in that theory and its modern adaptations was the utopian desire to deal only with the known and predictable, whether in the form of recurrent cycles which repeatedly bring with them the already familiar or in the form of a pre-established design for mankind. In either case, the incalculable individual element is reduced to a minimum: if the outcome is known, then this or that individual action, rooted in freedom, may be safely ignored as irrelevant. (236)

Utopian structure attempts something that is perhaps ephemeral. In trying to create perfection, utopists hope for immortality as well. This objective can have a destructive effect on the inhabitants of the system, and eventually on the system itself. As Molnar observes:

[The utopist] believes that by building a "system" and making it "permanent" he compensates for man's finiteness in time and space, for he feels that he has endowed the collectivity with the super-intelligence and super-morality 
necessarily lacking in individuals. But in this very process the utopian succeeds only in depriving the individual of his limited freedom and, therefore, of the value of his action. (236)

It can easily be contended that when individuals conclude that their choices are without consequence, they are more likely to make heedless decisions. This, on the aggregate level, would be a harmful influence in a society.

As we have seen, utopists' approach can easily tend towards sacrificing the desires of the individual. Most utopias are designed to optimize the functioning of the group, and only concern themselves with removing the individual's negative traits. They assume that group interactions can be orchestrated, while the internal motivations of individuals are much more difficult to direct and control. This perspective, while a natural outgrowth of the accessibility of group design versus individuals' design, misses a critical tenet of successful formulations. In the words of Frank Manuel, "A socially defined utopia loses its truth if it does not at the same time fulfill the person, just as the individually defined utopia loses its truth if it does not at the same time bring fulfillment to society" (Manuel 297).

This trend of emphasizing collective structure and the needs of maintaining the collective structure is pervasive and persistent amongst utopian works. Anthony Stephens has said, "Increasingly in the eighteenth century (utopian) fictional texts explore the problem that, as we saw, is already implicit in Campanella's Utopia, even if it 
receives no analysis there, namely the degree to which the institutions of any Utopia pose a threat to the self-realisation of the individual" (Stephens 13).

Raymond Muncy found that utopian inspired communes of the 19th and 20th centuries demonstrated this trend in actual practice:

Utopian communities sought to completely submerge the ego in the group, a task of such gargantuan proportions as to defy imagination. While they promised to provide freedom for their members, they made themselves slaves. Individualism, that vital corollary of freedom, was denied to all but the dictators who engineered the projects. For if individualism were allowed to express itself, collectivism was impossible. (48)

Rational plans implemented by rational minds became a prevalent trend in utopian constructions. Utopists were often accomplished intellects. Many observed great new developments in philosophy, industry and science. Their confidence in rationally orchestrated societies was founded in part on the tremendous speed and force with which other products of the rational intellect had generated change.

Bertil Martensson puts forth a description of the development of what he calls "utopian rationalism" in the nineteenth century. It was predicated not on religious or philosophical grounds, but on the economies of the industrial revolution and the new scientific determinism gaining credence at that time. Martensson states:

The belief in the superiority of impersonal and large-scale planning, the disbelief in the individual, and the suspicious attitude towards the emotions all fit nicely together with a positivistic ideal of science. Positivism could therefore very easily become allied with totalitarian ideas, as it would happen very soon in the revolutionary Soviet Union that so many Western intellectuals viewed with so much promise. (484) 
Especially at the turn of the century, utopists leaned towards solutions

administered by the state. The assumption implicit in this was that individuals could not solve their own problems. Krishnan Kumar observed:

What was common to all these philosophies, what united their critics over all other differences, was a scientific determinism that seemed intent on driving out any concept of individual will and individual freedom. The utilitarian and materialist cast of their ideologies denied any place and meaning to the 'soul' or to any other human attribute that could not be scientifically analysed and empirically observed. This left the way open to the rationally organized Scientific or Welfare State, run by the experts: the technicians or bureaucrats with the requisite scientific understanding of nature, society and man. The justification of such a regime was nearly always that of the Grand Inquisitor. The mass of the people are weak, ignorant, defenseless. They must be helped and protected, if necessary, against their own will and short-sighted selfishness. (119)

It is intriguing that so many utopists, often arch-typal liberal humanists and sensitive souls, could inadvertently create the same cynical proscription. Perhaps their visions were distorted by their sensitivity to the pain of the human condition. Perhaps the oversights were the result of the arrogance of their 'rational approach'.

These oversights were not solely the domain of the pure theorist. Men and women of action, who tried to realize utopian communities in their own time had to face the inconsistency of their visions, as well. This was certainly true of utopist colonists in the United States facing real challenges with real people in the early nineteen hundreds, as Charles P. LeWarne discovered:

Colony leaders tended to oversell their panaceas and attract more recruits than they could accommodate. Not unlike the society they protested, promoters sought people with technical knowledge and skills and willingness to work, even while they publicized colonies as havens for those who had found no place in conventional society. They thereby tended to attract the very persons least 
needed, while persons who had the desired skills were those least likely to seek sanctuary in a colony. (236)

Yet not all individuals in the vanguard of utopian thought were inspired by purely scientific or economic theories. There were even largely popular movements that emphasized freedom and self-reliance for individuals, particularly in the nineteenth century. But, these movements did not emphasize the contradiction, if they were detached enough to see it. Bertil Martensson has noted that, "Against this, one might wish to emphasize the virtues of classical liberalism. Unfortunately, the liberals were usually utilitarians. To the modern utilitarian, the happiness of mankind as a whole or the happiness of the nation, by definition, counted more than the happiness of any individual" (Martensson 484).

Utopian constructions are influenced by "sales considerations." To be provocative, utopists attempted to persuade their reader that their plans could and would be realized. Some utopists sought also to convince their audiences of the power that would bring their schemes into existence. This was done by suggesting that people in he proper system would all have the same, perfect, set of values. Implicit in this is the assumption that all people would interpret the same set of values in the same harmonious way. Even without addressing that rather counter-intuitive assumption, the notion of a universal system of values is highly suspect. As Ralph Dahrendorf states, "I have yet to see a problem for the explanation of which the assumption of a unified value system is 
necessary, or a testable prediction that follows from this assumption" (Kateb 111). Such sales-pitches have modest value in actual usage.

\section{Past Behaviors of Utopian Writers}

Utopian writers took a variety of approaches to convincing readers of the imminent likelihood of a utopia's creation. If asked why has a perfect society never existed before, the utopian asserts the existence of an inherent barrier. In Molnar's view:

The utopian mentality is marked, therefore, by the belief that mankind has not yet had the chance to make its own decisions and to live according to true standards of behavior. The utopian assumption is that man, potentially and ideally autonomous, has always been thwarted in the expansion of his 'real' nature by a conspiracy of priests, by superstitious beliefs or by a political class. (23)

Why such a system never spontaneously occurred somewhere at sometime in the many legions of societies that have existed is not brought up. If it were, the utopist would change the subject by suggesting that the unique aspect of his or her work will make possible the realization of a quantum improvement, and that all should want to participate.

Utopians seldom allowed for those not interested in participating in a utopian scheme. According to Martensson:

The utopian thinker naively assumes that all people will love the utopian existence once it has been realized. But what do you do with those people who cannot settle down to some complacently happy utopian existence? What do you do with the ambitious, the romantics, the rebels, the mountain climbers, the violent, the geniuses, the megalomaniacs, or the other antisocial nonconformists? (494) 
This lack of making allowances for square pegs and non-conformists greatly increases the vulnerability of the utopist to failure. The resulting system cannot allow the significant portions of humanity to pursue their own needs within the system.

\section{Tips for the Utopia Reader}

It is perhaps because utopias are presented as fiction that utopia readers can entertain a certain amount of "the willing suspension of disbelief." This attitude often is mandatory to consider a "What if. . ." question. To become fully immersed in the depicted image of a perfect society, a reader generally has to accept some sort of premise upon which the rest of the work is based.

This can be problematic. There is an essential difference in mind-set between granting an assumption for the sake of argument, and the fiction genre's "willing suspension of disbelief". An assumption granted is in actuality only temporarily accepted while its logical conclusions are weighed. The assumption will still receive review, and must ultimately be proved or disproved. But "disbelief" is not reinstated until the reading is finished. The original proposition is not necessarily tested.

Since speculation seldom stops at one step, however, the "what if. . ." questions often form a chain of assumptions; which compounds the problem. For example, any or all of the following might be combined. What if there were an island community established by an enlightened monarch? What if all the people voluntarily combined their property to form a classless collective society? What if marriage and the family 
were abolished? What if the educated and enlightened were given temporal power, rather than the bureaucrats, the nobility, the politicians or the otherwise ambitious? What if technology were so advanced that material plentitude were available to everyone? As multiple premises are compounded the variables multiply. This makes cogent testing of propositions more difficult.

Utopians assert these premises so that at the end of their works the readers can say, "Now if only the initial condition could be achieved, the rest would follow naturally." The difficulty, however is that abstract conclusions can not be automatically granted anymore than abstract premises can be automatically granted. The following example will demonstrate why:

What if we didn't need to breathe air to survive? A society could be formed using the bottoms of lakes, oceans, and rivers for additional living space. Less crime would occur, because people would be less densely packed into cities. Fishing and algae farming would be easier and increase food supplies, so people would not have to work as many hours in a day. People could not be murdered by drowning or suffocating, so there would be less murder and we would live in a happier world. Pollution of the air would not be a health concern so our factories could operate at lower costs, thus improving our economy. The improved economy would allow us more time to pursue readings of Kant and Zen meditation so that our society would be morally superior and decidedly tranquil. Considering all these benefits, it must only be the foolish, greedy, and bad people that continue to make us breathe air. If we were liberated from these bad elements, our true 
nature as non-air-breathing members of a perfect society would follow irresistibly.

Perhaps reason will convince them.

It is this form of loose reasoning with which the reader of utopia must contend. So often the later steps do not necessarily follow. Even if the economy were improved, readings of Kant might just as easily decrease. . . and so on. The compelling question after each assertion is "why would people react that way, rather than many other ways?" Also, if the initial questionability of the premise is addressed, much of the later logic can be discarded. Would it be in people's interests to sacrifice their autonomy and free will to a collective whole? Would the collective whole have a better understanding of, and ability to facilitate, each individual's needs than the individual himself? Would the collective whole have a direct interest in satisfying that individual's needs? Would there be a meaningful penalty to the collective whole if it failed to satisfy that individual's needs?

By asking himself or herself why these conditions do not, and have not, existed before, the utopia reader can proceed through a utopian text with a precise eye towards discerning what is plausible and what is specious. This should help elucidate the work's merit and save time in its evaluation.

Kateb writes how Dahrendorf explained that Milton Friedman's criticism of Lange applies to most utopian works:

For the most part, the crucial question, 'What observed facts would contradict the generalization suggested and what operations could be followed to observe such critical facts?' is never asked; and the theory is so set up that it could seldom be 
answered if it were asked. The theory provides formal models of imaginary worlds, not generalizations about the real world. (110)

That is telling and damaging to most utopists because they universally are trying in some way to affect the actual world. 


\section{Chapter Five}

This chapter explores the duality between the system's need to respect the individual and its need to receive commitment from the individual. This is envisaged through the ethical concerns of excess centralization, the practical concerns of contending with self-seeking individuals, and the factors necessary to build social cohesiveness.

\section{Against Centralized Planning}

As was said in Chapter Four, utopists, especially in the nineteenth century, brought forth a belief that rational planning and science could provide for the best society. These were products of the intellect, and implicit in this statement is the assumption that the most intelligent people would therefore be the most rational planners. Utopists tended to knit together various themes of their era. As shown in the works of Campanella, Fourier, Bellamy and Wells, utopists tend to confidently assume they themselves are most intelligent, and elucidate on their plans. Since the most intelligent are but a few, and yet their plans are best, planning must therefore centralized. So began the lack of respect held by many utopists for individual judgement and choice.

Collective planning was further supported by its perceived efficiencies. Since it was based upon science, there was little room for ethics. Centralization was considered superior to individual decision-making because it was rational.

Martensson prepares the ground thusly, and proceeds with his analysis of the flaw in the utopists' argument that a superior rationality exists. He argues that in judging 
rationality we judge both methods and goals. "What is the most rational method?" tends to be replaced with the question, "what is the best strategy?." But, he points out that a sublime strategist may still be deemed irrational if he chooses insane or unreasonable goals. Therefore, we are judging the decision-maker's world view.

Martensson says this leads to a lemma, "Not only has no one yet devised an objective manner of evaluating which worldview is the most rational one, there is no such method" (Martensson 499). He contends that either a theory is allowed to prove its own rationality (i.e., its worldview) which is a circular argument, or it necessarily invokes a metatheory to support it. But, how does one know that the metatheory is rational? In a different culture, a completely different metatheory may be deemed just as rational. If the metatheory is allowed to prove its own rationality, then that is a circular argument. It if invokes another metatheory, then how is it to be proved that the new metatheory is rational? This becomes an infinite regress.

Martensson concludes that while there may be a hierarchy of least to most rational ideas, to actually know which is most rational is beyond humankind's ability, and he urges humility on the utopian rationalist:

The most important consequences of the argument are ethical. Because no position concerning rationality can prove itself to be ultimately rational, the principle of autonomy takes over. Each person must be allowed to choose one's own life, as long as he or she does not deny other people the right to choose theirs. (501)

Autonomy allows individuals to make their own decisions in pursuit of their own wants, risk their own resources, receive the consequences of their own actions, and learn from 
their own experiences, to do it all better thereafter. Unmitigated rational planning flies in the face of this autonomy principle.

Perhaps the most emphatic utopists to use rational planning were the Marxists. While Marx claimed to be an historical empiricist, not a utopist, this author would contend otherwise. Marx's claim that true communism is the "final stage of history" can only reasonably be construed as utopist. Marxists see the collective as the organic priority for which all else must be sacrificed. They assume that the collective has needs that by the standard of strict utilitarianism are the highest priority. But the collective is not an organism with its own desires. The passion that fuels group activities is still contained within individuals. The individuals who are not advantaged by group priorities have no reason to pursue collective good on the margin. Their desires, having no opportunity to be represented or acted upon, are removed from the system, and so too is the motive force to produce good that could have thereby been harnessed.

\section{Supporting Individuality versus Selfishness}

A basic supposition of two of the three analytical tools presented in this work (testing by abnegation and affirmation) is that only individual desires provide driving force for the system (the system being an aggregation of those desires). It follows then, that the tendencies of individuals may have meaning and give predictive power. One such tendency is mini-maxing (i.e., actors attempt to make the minimum sacrifice to obtain the maximum benefit). Mini-maxing provides a competitive advantage both 
according to the theories of both Adam Smith and Charles Darwin. Freud would explain it in terms of the tension between Thanatos and Eros. B.F. Skinner would say it proved that behavioralism was valid, and it certainly does not seem to controvert behavioralism. People tend to repeat activities that are successful for them, and give preference to the most rewarding. Once they have reached a plateau in terms of reward, they reduce the effort expended until there is a steep drop off in reward. They have then found the "optimal" cost-benefit ratio and, provided it is still attractive to them, proceed to pay no more than necessary to receive that level of reward. Pity the poor planner who assumes actors will pay more. How can a system respect individuality without indulging selfishness?

The essence to a balanced and flourishing system actually is based on behavioralism in some respect. The system should be constructed in such a way that reward can not be extracted from it by an individual who does not contribute proportionally into it. Additional (marginal) reward should require additional (marginal) contribution. This proportional relationship allows the system to expand into high value areas, and withdraw from low value areas. This positive correlation is essential to providing the system with a means of adapting itself to new circumstances. The stronger this correlation becomes, typically, the stronger the system will then be. Where this author would differ from Skinner is in explaining why actors behave in a way that could also be described by behavioralism. It is rational to do so. They are rewarded for behaving this way. Individuals minimize the negatives and maximize the positives, thus 
having the best net quality of life. Not all do so, but those who do will be more successful, and become a larger percentage of the system as a result. Those who do not may only be slower at learning "where the cheese hides in the maze". All do what they do because it is assumed they have free will. Of course, in actuality there are different kinds of cheese in different parts of the maze and each "mouse" pursues only the reward

of value to him. A good system simply creates conditions under which the actors are rewarded for supporting the system. A viable system adapts itself to that end.

\section{How to Strengthen Commitment to a Social System}

Social systems require faith. Individual actors will only yield to the directives of system administrators if they believe the system will produce a meaningful good for them. This is social commitment.

Rosabeth Kanter offers three forms of social commitment; continuance, cohesion and control commitment. Each form is split into a positive and a negative sub-form. Continuance commitment, for example is the profit from continuing to associate while calculating the cost of ceasing. Kanter's terms are investment and sacrifice. This means that membership becomes more costly and is not given up lightly.

Cohesion commitment involves the development of emotional ties among members of the group, which has the direct effect of strengthening its cohesiveness relative to the outside world. Kanter's terms here are communion and renunciation. This means identifying more with those in the system, and less with those outside it. 
Control commitment involves the acceptance of values and norms affecting social control within the social system as one's own highest values. Kanter speaks of mortification of one's pride, and transcendence of one's own interest (Gardner 23-27).

LeWarne also mentions Kanter's theory of social cohesion in his study of turn-ofthe-century utopian colonies in Washington State. Kanter's commitment factors were evident in the few colonies which lasted more than ten years. Communion, renunciation, sacrifice, and mortification correlated with communes whose identity held them together.

LeWarne's observations about how Kanter's factors were applied can be summarized in the following manner. Communion with fellows formed a common image. Renunciation of alternate social systems increased relative commitment to the system. Requiring sacrifice to be able to join the system caused individuals to decide firmly in their own minds to value the social system. Mortification involved the process of forcing a person to reduce his or her sense of self to relatively elevate that of the community (much like hazing in a fraternity). Transcendence (which was apparent in none of the Washington colonies) comes when charismatic leadership, awe of the institution, clear-cut compelling ideology or something else lifts the members beyond their own concerns to serve the greater purpose of community (LeWarne 237-38).

It is striking that these elements can easily be found in some well established social systems. For example, land and freedom seeking immigrants came to North America, and sacrificed to make the ocean voyage. Certainly the Puritans developed 
communion and forced the mortification of self upon their members. The War of American Independence can be understood as a fairly clear statement of renunciation. The zeal that came out of the war may have also provided transcendence (or that may perhaps be too ephemeral to identify).

Alternatively, a community such as a nunnery can also be seen to use these techniques to generate and reinforce commitment. This is done by requiring sacrifice of sex, wealth and sometimes spoken words; requiring group activity at vespers, meals, and chores; requiring renunciation of worldly attachments, including birth name; requiring mortification in humbling self before superiors and physical symbols; and offering a detailed ideology to facilitate transcendence. Nunneries certainly appear to have been stable social systems.

Again, these factors are an amalgam of rational and subjective wants. The critical realization is that the emotional component of social commitment is palpable. To the would-be reformer, the implications of respecting autonomy, harnessing mini-maxing, and building social commitment are pervasive and widespread. They provide both challenges and opportunities to the largest as well as the smallest existing and proposed social systems. 


\section{Chapter Six,}

In this chapter, we will categorize the major flaws to which utopian proposals are prone.

This list is to be used to identify weak elements in reform proposals and, taken as a whole, to assess the prospects of the proposed reform itself.

There is a primary reason to categorize the major flaws to which utopian proposals are prone. Our intention here is to compare any proposal of systemic reform to that short list for more accurate rapid evaluation of its viability. This should result in a thumbnail-size quality test for reform proposals.

With a quick test for flaws, greater respect can be lent to those works which pass the test; incomplete proposals, utopian and otherwise, can be checked early by the creator and amended or discarded. With a quick test for flaws, scholars and decision-makers can concentrate their energies on proposals with viable solutions and reasonable trade-offs.

In order to frame this task, several limits and definitions should now be elucidated. We are not looking for the kinds of shortcomings that are quirks of history, particular to the personalities of the implementors, or due to ill-fortune. Rather, we are looking mostly for the flaws that cannot be gotten around no matter when a reform is enacted, no matter who the implementor, even under conditions of relative good fortune. That said, we will assume that the individuals who make up the system are generally rational humans typical of those who navigate their way through systems today. 
The following assumptions give significance to the various effects of categoric flaws. If an adjustment to the structure does not produce a meaningful change in the behavior of the system's elements (e.g., the people within it), then it fails as a proposal of systemic reform. If an adjustment prevents a system from being able to continue relatively indefinitely, then the reform has weakened system viability. If a structural change prevents the system from significantly affecting its elements, then the system will become irrelevant to its members' behavior and fail. If a reform of interconnected subsystems strengthens one and weakens others, then evaluating the reform's overall merit is likely to be subjective and cumbersome.

What would have been ideal to achieve is a mutually exclusive list of flaws that encompasses any objection that can be made to a proposal of systemic reform (or systemic construction). The list generated here is, candidly, a working draft. But with further review it can be matured.

\section{Categories of Flaws}

1) The fallacy of the last move: assuming that once changed, the system will remain static.

2) The fallacy of fortunate oversight: neglecting problems for which the proposer has no solution.

3) The fallacy of homogeneity: assuming that all actors within a system have similar preferences.

4) The fallacy of static contentment: assuming that what satisfies actors today will satisfy them tomorrow. 
5) The fallacy of baseless extrapolation: assuming that system elements can be expanded beyond their current equilibriums.

6) The fallacy of free transition: assuming that the effort necessary to create a new norm is nominal and finite.

7) The fallacy of perfect isolation: assuming that one element of a system can be changed without necessitating change of or disturbing other system elements.

8) The fallacy of the end of politics: assuming an end to competition for the distribution of limited resources.

\section{Fallacy of the Last Move}

Many plans target only current levels of problems, and make no allowances for future problem levels. These plans are customized to contend with current conditions, implicitly assuming conditions will not change. The plan is designed to deal with problems as they now exist, and the plan often smugly implies, "if the problem changes, it is the people's fault." This is typical of the fallacy of the last move. This approach is especially specious when we are dealing with theories of human nature which do not hold that people adapt to their environment.

In games theory, this fallacy is a standard. When an athletic team changes its offensive strategy to exploit a defense's configuration, that may provide an advantage temporarily. However, it is understood that the defender will adjust defensive strategy to minimize the effectiveness of the offense. 


\section{Fallacy of Fortunate Oversight}

In their enthusiasm to offer an elegant solution, many planners are faced with the difficulty of determining how to acknowledge any imperfection in their plan. Whether it is a blind spot of the theorist, a natural tradeoff in his or her tactic, a poorly recognized technical phenomenon, or simply a difficulty that has yet to be worked out, many planners are mute on subjects for which they have no answer. The difficulty with this in

a thorough search for truth is that planners will weigh the perceived merits of their plans against the perceived disadvantages, and then pass judgement. If they have not fully acknowledged the range and depth of the disadvantages, theirs will then necessarily be a biased and potentially erroneous judgement. There are a number of phenomena that are typically associated with this fallacy. Friction, chaos, disfunction, subversion, inertia, ignorance and change all resist conventional approaches and hence are often ignored by planners designing "clean" solutions. The Prussian military theorist Clausewitz described "friction," in particular, as a force that began to break plans down as soon as their implementation began.

\section{The Fallacy of Homogeneity}

Planners are prone to simplified assessments of human wants because it simplifies plans to accommodate those perceived wants. The logical extension of this is to assume that all actors have similar preferences and are satisfied by similar solutions. The difficulty here, however, is that offering solutions in more areas makes it less likely that 
this assumption of homogeneity will hold true. Many planners offer broad-ranging solutions that will affect most participants in a social system in a number of ways. This approach is difficult to succeed at, and often results in the fallacy of homogeneity.

A common style of proposal which succumbs to this fallacy is one utilizing centralized planning. Centralized planning works best when all pertinent information can be centralized and acted upon. It requires much less work if elements are standardized. Thus, the design and construction of an automobile can be efficiently coordinated from one factory working with dozens of suppliers. Maintenance of human beings, however, is not as simple.

\section{The Fallacy of Baseless Extrapolation}

Would-be-reformers often recognize a good thing in the status quo. In their eagerness to see it proliferate, they often fail to see the factors which place it at its existing level. Since practical reformers do not attribute to themselves the power to call resources into existence, this fallacy is more prone to occur in speculative plans. Any reformer can fall into the trap of assuming that whatever exists today can be made to exist in double the quantities tomorrow. It seems like an assumption based upon logic, but it is not.

There are a number of phenomena that work against it. Diminishing returns, limited supplies of critical resources, pareto optimality (i.e., the point along a curve at which net benefit declines whichever direction is followed) and other principles all resist 
the expansion of some goods or services beyond current levels. Occasionally this merely complicates the issue of providing services, or expands the scope of action needed to bring the solution into being. However, that increased activity can be enough to kill the plausibility of an otherwise simple plan. At other times, the expansion of those goods and services is simply not possible with current technical and material resources.

\section{Fallacy of Static Contentment}

Many utopian plans target a very specific need and assert that once it is satisfied, society will then be content and, ergo, perfect. Considerations about the diversity of needs amongst different individuals aside, there is still a problem. What these plans do not consider is that wants within an individual are subjective and dynamic. What suffices to make a starving man happy today, will in no way impress him as a well fed man tomorrow. Needs change over time within the same individual.

Psychologist Abraham Maslow's theory of the hierarchy of needs lays this out very clearly. Once a person has met his or her need for survival, he or she moves on to the need for security. Once secure, he or she moves on to the need for love and belonging. Once loved, he or she moves on to the need for esteem. Once esteemed, he or she moves on to her need to be self-actualized (i.e., transcendent; enlightened, fulfilled, at his or her peak state of being, etc.) (Coon 314).

Any plan that targets a limited set of objectives (e.g., assuring survival and security) will find that its participants still have needs, frustrations, reasons to be unhappy 
and reasons to strive after the plan has been enacted. The plan may be very valuable, but it does not bring the end of yearning. And if the plan absorbs most of the resources that are available (including those that may be used to pursue other needs further up the hierarchy of needs), it will fail to allow for the pursuit of needs as they change.

\section{The Fallacy of Free Transition}

Reformers often assume effortless compliance to a new plan, without understanding what price was paid to establish current practices. The weight of tradition, inertia, and habit must be acted against. This can require great effort. Exhorting people to remove old habits and build up new habits to a self-sustaining critical mass can be very costly. Many factors that are not under the control of the arch-typal decision-maker are involved in such an endeavor. Thus, the cost of change is not certain, and the realization of change is not guaranteed.

This can be devastating to a plan. When the benefits of change are marginal, they may not exceed transition costs. The plans which are most susceptible to this flaw seem to be those which contain myriad small codicils regulating general behavior toward certain (often ironically "efficient") ends.

\section{The Fallacy of Fractured Equilibrium}

Reformers often assume that one element in a system can be increased or decreased without affecting the levels of other elements. This causes unrealistic 
assessments of the consequences of change. for example, assuming that welfare grants can be increased without spurring an increase in the number of people seeking those grants is a typical example of the fallacy of fractured equilibrium. Current equilibriums are achieved because of a tension between the forces seeking something and the forces resisting it. When a change occurs in any part of the equation, a new equilibrium will be achieved. Very typically, in equilibriums influenced by legislative decrees, there is no elasticity to adjust to supply and demand, and hence a pressure is created to produce more consumers of an artificially low-priced good. If the law is not adjusted, the society is.

\section{The Fallacy of the End of Politics}

Many utopists assume that politics will disappear in their perfect system--that people will stop competing for more of the common pie, just because there may be enough for each. Human wants, it seems clear, are not quieted by sufficient minimum standards. Some actors will seek as much from the common supply as possible-especially if the cost is only exhortative rhetoric.

Contentious issues will continue to exist. Legitimate differences of opinion about the distribution of limited resources would also likely continue to exist. Diverse opinions about the best direction in which to steer and adapt the system will probably also persist. Cleavages that perceive themselves to be under-serviced will likely seek new administrators. These phenomena all call for politics. 
Additionally, in all manner of societies, there have always been those ambitious actors who compete for status or power, if not for material goods. The desire of these "alphas" is not for security, but for supremacy. For these actors, politics will always have a purpose. 
Chapter Seven

In this chapter we will describe testing a reform proposal by affirmation. The necessary conditions for systems to exist will be listed and described.

Testing by affirmation involves gauging how well a proposed system pursues seven basic subgoals en route to attempting to provide social contentment. If the proposed system is being compared to another proposal, or to an existing system, then the strongest results in this test should indicate which system will deliver the greatest social contentment. Admittedly, any such assessment will necessitate high degrees of subjectivity and speculation. However if an array of analysts arrives at similar conclusions by means of this test, then that subjectivity, at least, can be corrected for. Speculation about the theoretical is without recourse.

Why list the necessary elements of a viable and sustainable system? There are many reasons: to help scholars and decision makers separate serious from incomplete proposals; to recognize its characteristics for a greater understanding of how change may be achieved and of whether a proposal on the table has the necessary elements; and to bring attention to the elements that need fixing in order for a mostly viable proposal to succeed.

The particular distinction of this method of evaluating social systems is that it assumes the self-directed actors are the only ones who can correctly say what their desires are. Those desires will vary, but as long as this method acknowledges that that is 
where the motivation to act originates, it always has an authentic starting point. All other social interactions follow from the desires of the self-directed actors.

Social systems must contain the following elements: actors, resources, and communication. Generally, only a fraction of the actors will act as system administrators, aggregating resources and desires into actions intended to produce goods and conditions desired by the grass-roots actors.

The necessary condition for a social system to be sustainable is that actors perceive sufficient comparative benefit to agree to continue supporting the system. This is enhanced by actors' commitment to, and faith in, the social system. Typically this commitment contains both subjective and rational components.

To have the greatest chance of earning the actors' support, the system bias should inherently strive to maximize the following seven aspirations:

1. Resource efficiency

2. Proportionality of benefit distribution

3. Positive pressure to create resources

4. Positive pressure to create social goods

5. Accurate aggregation of individual desires

6. Enactment of highest value/priority benefits

7. Appropriate limits of the system 
Systems which have relative success in maximizing these characteristics will approach utopia in their time.

1. Maximizing resource efficiency occurs through minimizing the overhead costs incurred in the resource aggregation process, and by maximizing the benefit yielded when expending the resource. Extracting the resource (taxation) and aggregating the resource (administration) should require the smallest percentage of the resource possible. Maximizing yield, or getting "the most bang for the buck", is essentially focussing the resource primarily on activities that directly produce a benefit and away from activities that do not.

2. Maximizing proportionality of benefit distribution involves returning benefits to similar percentages (or greater) of the population that contributed the resources. This appropriateness insures that the social system directly benefits its supporters. This in turn reinvigorates the grass-roots actors' willingness to provide support for the system. Support may come in different currencies from different cleavages, but the benefit should return approximately in the same or greater degrees to those cleavages or more. That is, after all, the payback implicit in the social contract.

3. Maximizing positive pressure to create resources involves (on the whole) building the incentive for, and ability of, the actors to create resources with which to provide for themselves. The more autonomous the actors are, the less they will burden the system for the essentials of survival. The greater the average surplus of resources becomes, the less painful is the average sacrifice of the resources that are necessary to 
operate the social system. The greater the average surplus of resources is, the higher the quality of life, compared to that of participants in other social systems will be. The greater the overall pool of resources becomes, more options are available to the system administrators to increase social contentment.

Some benefit distributions may, however, have a negative effect upon actors' incentive to produce resources (e.g., subsidizing those who are not employed). Such benefit distributions have to be dealt with prudently, lest they cause a marginal downward pressure on resource production. If such a marginal downward pressure were to be self perpetuating (and grow faster than other pressures), the net resources in a system would decrease, as would the quality of life and, very probably, social contentment.

Actors tend to pursue wants at the easiest source of fulfillment until a counterpressure discourages it. Typically, this is adjusted by supply and demand. However, if the system creates an inelastic, artificially low price for a commodity, demand will increase for that good, thus taxing the system. This may continue until supply runs out, thereby limiting consumption via rationing.

4. Maximizing positive pressure to create social goods involves arranging the system in such a manner that system administrators must (on the whole) maximize the benefits produced by the system to have their own needs fulfilled. The system will ultimately use some sort of feedback loop (i.e., popular elections, public opinion polls, peer pressure, status contests, lobbying) to clearly connect the good that an administrator 
does to the fulfillment of needs which the position of system administrator facilitates. This consideration generally argues against insular administrators who lack accountability to the grass-roots actors. In any event, the system exists to increase benefit, and so must be wielded to that end. Incorporating incentives for those who steer the system to direct it towards maximum social benefit enhances this.

5. Maximizing accuracy of aggregated desires involves collecting valid and appropriately weighted impressions of individual desires, and aggregating those desires with minimal distortion. In order to provide for social contentment in a social group with a diversity of wants (i.e., most social groups), objectives need to be consolidated into the smallest number of effective plans possible. The desires of the actors are what matter, since social contentment can only be judged by the actors in the social system. Therefore, any plan which purports to "know" what the actors want without consistently consulting them is suspect.

6. Maximizing enactment of the highest value benefits involves expending resources first on benefits of greatest significance to social contentment, and then descending in priority order down the list. Since human wants can always exceed human resources, it is essential that resources be budgeted and expended in priority order. Determining priorities (the stuff of which politics is made), while perhaps difficult, is facilitated by the application of items one through five above.

7. Limit the system at its point of Pareto Optimality. Most political struggle is posited to occur at the place on the list where a line is being drawn, after which needs 
will not be addressed. This line is the place to stop extracting and spending resources.

The indicator of this is that the cost of the good created exceeds the contentment received (the willingness of those holding the resource to yield it rather than spend it in their own way). Systems which draw this line well create as much contentment as possible, without reducing it in that pursuit.

Systems do well to communicate what the limits of the social system are, so that actors understand what they may reasonably expect from the system, and what they must seek elsewhere. Creating this consensus on the limits of the system avoids attempts to utilize the system for what it is not well constructed to provide. This too optimizes social contentment.

\section{Considerations for Application}

To begin to understand how well a proposed reform addresses the seven subgoals, a few simple questions can lay the foundation of the framework. They assist in understanding the intended function of the system, and where its priorities lie.

1. Why do actors contribute?

Why do they not abuse the system?

2. Why do administrators serve?

Why do they not abuse the system?

3. How do administrators collect information?

How do they compare the needs of different cleavages?

Why do they distribute benefits proportionately?

How do they define the limits of the system? 
4. What is the good produced by the system?

5. What is the cost?

In resources?

In restrictions?

In opportunities foregone?

6. What balances each function of the system?

\section{Accurate Aggregation of Information}

System administrators need accurate and useful information to produce relevant benefits. Information is key to servicing actors' desires. However, a system administrator needs to know more than just what are an individuals' desires; the administrator needs to know how intense those desires are. In addition, the administrator needs to know what the individual is willing to contribute to satisfy those desires; what effect this will have on other actors and the society as a whole., and how long these desires last (or if they will soon fade). This is a lot to know.

Information about desires must be aggregated. The complexity of desires within even one person can be dizzying. To act, information about how to satisfy must be refined into workable forms: vectors combined of similar yearnings, charter busses carrying just passengers interested in that particular route--bandwagons, if you will. This process of combining myriad individuals' wants into a minimal number of packages is called aggregation. 
Cleavages are a common way information is aggregated. The metaphor of the vertebrate animals' eye comes to mind. The information from hundreds of thousands of light receptors would overwhelm the processing power of the mind if it were not aggregated. Thus the optic nerve is "hard-wired" to pre-process information into groups and patterns which are sufficiently simple to be interpreted by the brain in "real-time" (i.e., in a manner that allows full interaction with that which is observed). In most polities, the part of the optic nerve is played by cleavages. The actors form into cleavages which are of reasonably uniform opinion about a certain desire. Bit they may form into an entirely different cleavage a moment later. Actors may be part of several cleavages at once. Just as an object viewed may simultaneously be a box, a green thing, a moving thing and a bright thing, so too an actor may simultaneously be a Republican, an NRA member, a retired person and a New Yorker. Of course, optical illusions can occur. The brain can become confused. And, an especially successful cleavage can reprogram the brain. That is a form of transferring information, however.

Distortion occurs when feedback only comes from a minority of cleavages. That minority may receive the top 10 desires on its list, while unrepresented cleavages have only one or two, yet their top five perhaps could provide more "benefit" for the resources expended than numbers six through ten of the well-represented cleavage. Benefit can only be measured in terms of the desires of the system's participants.

Accurate aggregation of individual desires requires a true mechanism, faithfully used. The democratic process is one such mechanism. A head of household 
communicating sensitively with family members and assimilating their wants is another. In the future, instant straw polls via electronic mail may be yet another mechanism for aggregating individual desires.

Whatever mechanism is used, it must measure the frequency and the amplitude of the "wavelength" of aggregated desires. That is, the direction of the desire, and the intensity of the desire must both be understood in order for the possibility of satisfying it to exist. Most importantly, direction and intensity of desire must be known so that, when aggregated, the most urgently-felt desires can be addressed first.

Since administrators will have discretionary authority over interpretation of the aggregated data, conclusions about its meaning depend upon faithful use of whatever mechanism collected it. Wisdom, temperance, and good fortune are valuable, too.

\section{Comparative Advantage via Positive Pressure to Create Resources}

Preserving a net positive pressure to create resources involves creating stimulating conditions for production, and suppressing conditions that would diminish production. Positive pressures to produce resources and social goods help systems maintain equilibrium. When a system is not self-correcting about consumption and production, obtaining equilibrium becomes more costly.

If a public good is given at no marginal charge, then supply and demand will not regulate its consumption. When cost is near zero, even those with the weakest demand may still consume. Those with a vigorous demand may consume well beyond the point 
where the cost is seen as worthwhile in leading to social contentment. Abuse of the system may constitute systematically minimum-maximizing to such an extent that the system is overburdened and under-supported on the margin.

Whether it be through per unit use fees, coercion, or rationing, some procedure must be put in place to avoid the tragedy of the commons. This phenomenon occurs when a group resource costs less to access than an individual's personal resource, so that the common resources is plundered and exhausted. Access to the common resource must in some way be limited. Fees, coercion and rationing all require resources to communicate and enforce them. To some extent, efficiency is always curtailed by the restraints placed upon consumption to prevent over-consumption. Supply and demand appear to be more cost-effective at limiting consumption to those receiving the highest value from it. However, it is clear that supply and demand will not work in all cases (e.g., welfare for children, primary education, public defenders).

Thus when an analyst asks, "Why do actors contribute?," the questions posed are what the actors receive that is desired and what stimulates and requires the actors to contribute a reasonable "minimum" to receive this. The further question, "Why do actors not abuse the system?," asks what conditions are in place that will prevent the actors from seizing more of the benefit than is proportional, or paying less than is needed to maintain systemic equilibrium. 


\section{Comparative Advantage via Preserving Net Positive Pressure to Create Social}

\section{Benefits}

It is important to note that system administrators (elites) are self-directed actors as well. They have aspirations which they hope to fulfill via the system. The significant distinction between them and other actors is that they hope to fulfill their needs by working the system, rather than being worked by the system. The common actors can still have a symbiotic relationship with the system administrators, so long as the system administrators perceive they need something regularly from the common actors.

Administrators are actors, too. They are perfectly capable of mini-maxing. The effect of this in their case is to create minimum social benefit, and receive maximum reward from being a system administrator. Thus, the question, "Why do administrators serve?", is posed by analysts seeking to understand what desire is fulfilled by serving the system, and what reward an administrator receives on the margin, for producing a marginal increase in social benefit.

Examples abound to demonstrate this point. The classic bureaucrat receives nothing on the margin for improved service, with the possible exception of prestige and promotion, but these are longer term and less immediately connected to creating additional social benefit. One difficulty associated with elected representatives is that they are graded on a pass-fail basis, with little marginal gain for exceptional performance. They may perceive in their own desires a marginal prestige or satisfaction, but this is not uniform. 
Administrative actors may consolidate into subsystems to deliver consolidated desires and resources to administrators. Further administrators may be a team. If they are a team, they need balance within their sub-system, which may be a social system of its own that affects the output they produce. While some administrative subsystems exempt elites from the constraints of the system at large, others require additional restraints in exchange for whatever it is they grant the administrators.

\section{What is the Good Produced by the System?}

The good that is produced by the system is the system's reason for being. No system exists in and of itself. No system can persist indefinitely without the support of its constituents. The good received by the constituents is their reason for supporting the system. Thus, much can be understood and characterized about a system by examining the good it produces, how and for whom.

Such good must be valuable proportionate to its cost. If the system provides education, but consumes fifty percent of a gross national product in doing so, it could survive only in the most rarified climates. If the system provides cross-walk attendants at two percent of the gross national product, but private attendants could be hired for one percent, that good is not proportionate to its cost.

The system must be relatively effective at providing the good. Over arching reform plans often try to meet all needs. Their authors seek to service all wants and receive all fees. This is difficult to manage in a market economy because of competition. 
Large conglomerates often pursue a customer base because it is a growth market, and abandon a niche because their way of servicing it proved uncompetitive. Seldom can one enterprise be all things to all people. When examining a reform proposal, we should consider if the services intended to be "sold" would actually be the reasonable way for the proposed constituents to "buy" them.

\section{Is a Benefit Worth the Cost?}

Cost-benefit analysis requires one to know both the cost and the benefit of a proposed good, and then adjudicate the value of their correlation. The ideal is zero cost for infinite benefit, and the nadir is infinite cost for zero benefit. In practice, administrators seek relatively favorable cost-benefit ratios. To achieve this, they must seek specific information about both costs and benefits.

Benefits are ultimately judged subjectively by those receiving them. There is a rational component to that judgement, however. Also, those recipients will often preapprove benefits for which they lobby. Qualitatively, some benefits are seen as clearly superior to a status quo they may replace. Administrators are most fortunate to have a choice that is superior in all ways to their status quo; rational assessments can result. These are only a portion of the possible and, indeed, likely scenarios, however. In the end, administrators are forced to intuitively estimate the degree and breadth of benefits they are considering providing. 
Costs are measured in three ways: behavior constraint (behaviors disallowed), opportunity cost (opportunities foregone because resources were directed elsewhere) and resources ceded. Since costs are measured in three different variables, actors may vary markedly in their tolerance of the costs, depending upon their prioritizing of the three variables. Those for whom freedom is the highest priority may not mind high taxes, as long as they feel unrestrained in their daily life. Paternalists may prefer large amounts of law and order but be very uncomfortable with high taxes. A teacher may be very comfortable with spending high taxes on large amounts of law and order, but not if it means decreasing spending on education. Part of the cost of a decision is thus subjective. This can even change over time. The material cost of a decision, however, will be more tangible. This will be factored into how efficiently a social good may be provided. Efficiency, if it were quantifiable, would be measured by dividing the benefit by the cost. The greater the benefit is compared to the cost, the more efficient the system could be said to be. Yet, a very modest benefit may have an infinitesimally small cost, and thereby be "efficient" without being extensive enough to be effective. As needs change, many different levels of benefit and cost will be compared. Typically system administrators are trying to maximize satisfaction with the limited resources available to them and trying to be efficient by maximizing benefits and minimizing costs.

System administrators typically rely upon "return on investment" numbers most heavily because such figures lend themselves more readily to quantification. Some amount of economic theory can be applied and some level of predictability attained. All 
three variables can be very uncertain, however, when administrators are planning. Of particular note is the special economy provided by minimizing constraint. Since constraint usually requires the active expense of resources to prevent rather than produce a behavior or good, the least constraint that is necessary produces greater efficiency in the system (in terms of return on investment of resources ceded to the system).

\section{Equilibrium--A Balance of Pressures}

A system that cannot sustain equilibrium tends to be more costly to maintain. Equilibrium is predicated upon the system providing valued and proportional return on investment to sufficiently large cleavages to be desirable. System equilibrium is enhanced by 1.) system administrators and common actors having a responsive symbiosis, and 2.) systems being limited to distinct responsibilities that they are well suited to fulfill.

In simple terms, systems require proportionality of production and consumption. Given that it seems within people's natures to consume but not necessarily to produce (having evolved most of our pre-history consuming the fat of the land, not the labor of the hand), then systems can only retain a proportionality if there are spurs to produce and restraints on consumption.

There are many examples of such spurs and restraints. Requiring people to pay for their food is a constraint. Requiring people to work for their pay is a spur. Requiring elites to satisfy the masses for their status is a spur. Limiting what the elites may do with 
their status is a constraint. Without including minimum contributions and maximum disbursements, there are no proportional limits on natural appetites for leisure and consumption.

\section{Adaptability and Change}

Systems change. Usually, systems evolve because of changing environmental conditions and changing preferences. Sometimes systems change because of violent outside influences competing for the same resources, or imposing new restrictions. Sometimes the needs of the actors change sufficiently to alter the system (e.g., there is no longer a theocracy in Egypt or New England, but there was recently one again in Iran). Because therefore, no system can be all things to all people, systems face competition from new alternatives, rediscovered traditions, extra-cultural approaches and other sources. These press for change. 


\section{Chapter Eight}

Ad hoc analysis of systemic reform proposals seeks to reach a general conclusion by commenting on the proposal's most notable parts.

Most approaches to analyzing reform proposals draw in part upon improvisation and in part upon techniques used by the analyst with some previous success. The analyst brings forward his or her knowledge base, which is sometimes considerable, and scans the plan for indicators of success or failure that have been discovered before. To the extent that the plan being assessed is unique and unprecedented, the analyst searches for new indicators of success or failure. This is necessarily invented as the analysis proceeds.

Ad hoc analysis also involves free associating. This free associating can be very insightful. Metaphors can be transferred from one area of study to another. A command of psychology, philosophy, economics, history, anthropology, finance, games theory, advertising, sociology and even competitive sports can be brought to bear and made to serve in the assessment of new reform proposals.

The strength of ad hoc analysis is that it is customized to whatever proposal it is applied. This allows for valuable insights at levels other than the system itself. Thus the most salient observation about a particular utopia could be that its author was an autocratic, megalomaniacal intellectual snob whose edicts are heedless of the desires of actors in a real society. If that realization is made early in a large-scale study, then 
attention may thereby be focussed more productively. . . perhaps elsewhere. Ad hoc analysis is also free to pursue insights at any level because it seeks an approximate answer to one primary question: "What, if anything, is of value in this proposal?" Ad hoc analysis of systemic reform proposals encourages prima fascie "gut reactions" and thereby lends itself to colorful rhetorical assessments. It is free to pay particular attention to whatever is outstanding about a proposed plan, whether that be negative or positive. But as soon as it can characterize the outstanding traits of a proposal, its job is completed. 


\section{Chapter Nine}

In this chapter we will explicate the criteria by which our sample case utopian proposals were selected.

Since not all utopias are written for the same purpose, they cannot all readily be compared on only one dimension. While many are intended by their authors to be enacted literally, others--and certainly some of the best known--are intended only to be statements of principles and goals that the author advocates. Dawson's three categories of utopias, listed in Chapter Four, assist us at selecting only programmatic utopias for this analysis. Utopias espousing only principles are unsuitable for this analysis. They typically are critiques of some status quo, often general but occasionally particular. They attempt to illustrate the way a perfect world should "feel", if not the specifics of its construction. Classical utopias including Plato's Republic, and many renaissance works including More's Utopia, were such exercises of principle rather than of civic engineering. These will be designated "High Utopias" and we will forego formulaic analysis of them because they were not strictly intended as reforms (i.e., since they are calls to action without a plan to enact).

Also to be excluded from evaluation are escapist-fantasy folk utopias. The isle of Cokayne, the isle of limitless plenty, a planet eons in the future with unrecognizable technology, a city built of unobtainium, and other physics-defying communities will be excluded as not advocating a reform so much as an afternoon away from worry. While 
they may include valuable social commentary or thematic insight, they are too far removed from the constraints of pragmatic reform proposals to be amenable to similar forms of analysis.

This leaves for our evaluation utopian plans which the author intended for this world to enact almost literally. Since this presumed intention is sometimes debatable, however, we will endeavor here to pick only the most-probable cases. Occasionally, flaws found in plans outside this scope will be referred to when they vividly illustrate a particular category of flaw.

\section{Criteria for Selecting Case Studies}

Several factors beyond the guidelines above entered into the selection of the following case studies:

First, to avoid historical bias, works were selected from the seventeenth, eighteenth, nineteenth and twentieth 20 th centuries. This cross-section will also span several trends in the genre.

Second, utopias which received a considerable reception by the public and scholars have been selected to ensure a certain breadth of review and cross-referencing.

Third, utopias with a cross-section of scales have been selected. The level of the system may be as small as a township or as large as the planet.

Fourth, obtaining a gender balance among utopists is awkward because before the twentieth century there were very few female utopists. In the twentieth century, they 
tend to write High Utopias or escapist utopias. Still, some examples will be drawn from their work.

Fifth, utopias written in Italy, France, England, and the United States were selected to provide a broader geographical distribution.

Sixth, obtaining an ideological distribution among utopists also presents certain problems. Most could be described as liberal humanists. Some advocate individuality to the point of anarchy. Others design a society so structured as to outlaw most expressions of individuality. Some are progressive to the point of believing that new technologies and teachings can solve all problems. Yet, others desire a return to a simpler, more pastoral past, made more idyllic by a few technical innovations. Conservative or progressive, individualist or paternalist, elitist or populist: the contrasts are there to be found. We will endeavor to distribute our cases across these poles.

It is therefore hoped that with this spread of characteristics, the following list of categories will not be specific to any one genre, time period, or political ideology. 


\section{Chapter Ten}

In this chapter Campanella's City of the Sun will be examined for the plausibility of its social system.

\section{Campanella's La Citta del Sole}

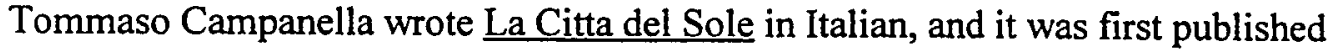
in 1602. Campanella "was a Dominican monk and a revolutionary who spent almost half of his seventy-one years in prison" (Stephens 4). He failed to bring about his social designs with revolution, and wrote this more radical work from prison. His activism supports the contention that he wanted to see his ideas enacted literally in this world.

The goals of the system La Citta del Sole would bring to life were an unselfish society, an educated, knowledge-based society; and an aesthetically and culturally-preeminent society with a hegemonic imperial power base.

Campanella was also a philosopher, mystic, and astrologer who imagined his perfect city state run by a benevolent high priest. He would create three chancellories: Power, Wisdom, and Love. Power would carry out Campanella's imperialist, hegemonic military program. Wisdom would proliferate and advance the sciences. Love would mandate and monitor Campanella's astrologically and physiologically-inclined eugenics program. Stephens has observed that, "If one can not help thinking of Orwell's Minpax, Minitru, and Miniluv, this is not altogether inapposite, for under Campanella's three ministries conformity in daily life is rigidly enforced" (Stephens 5). 
Yet there is much that is progressive in Campanella's plan. According to Stephens:

It has a hierarchy chosen on the basis of individual merit alone, and male and female roles are merged in all vocations as far as possible. The state rests on the twin principals of the abolition of private property and the abolition of the family. The whole city is laid out as a giant educational machine. (4)

While there is no sense that material demands permit it, work is limited to four hours per day for citizens, and all labour is regarded as a dignified pursuit.

Perhaps some of this is allowed by all citizens communing with each other by being required to live in dormitories. Campanella, perhaps trying to out-do Thomas More, details a labor schedule that emphasizes leisure and personal development:

In the City of the Sun, while duty and work is distributed among all, it only falls to each one to work for about four hours every day. The remaining hours are spent in learning joyously, in debating, in reading, in reciting, in writing, in walking, in exercising the mind and body, and with play. (23)

Leisure not withstanding, the similarities to Lycurgus' Sparta are striking. Private wealth is denied. Communal living, rigorous training, eugenics, and a strong military are compelled. The Spartan economy was buoyed by slave labor, and Campanella is not averse to slaves working on the perimeter of his city. However, he adds the extensive pursuit of science and mysticism to the Spartan formula. Campanella removes the family entirely. All conceptions are arranged and controlled, and all children are raised in nurseries. Campanella wrote, "Children are bred for the preservation of the species and not for individual pleasure, as St. Thomas also asserts. Therefore the breeding of children has reference to the commonwealth and not to individuals" (Campanella 20). 


\section{Test by Abnegation}

Campanella does not address the cost of transition. Stephens notes that, "The Citta del sole contains not the slightest indication as to how the social structure of the Sun State might relate to that of the author's own society. . . let alone evolve within it" (Stephens 12). Since Campanella never attempts to describe how this city will come into existence, we can not say whether this is the fallacy of free transition, the fallacy of fortunate oversight, or simply something not to be considered because its omission is considered to put the responsibility on the reader to solve the problem.

Campanella describes a very particular existence with many tradeoffs and sacrifices, but assumes that all within his utopia will be equally happy. This is definitely an example of the fallacy of homogeneity. There is little likelihood that all citizens would be satisfied by the sparse lifestyle--dedicated primarily to intellectual pursuits-offered there.

The fallacy of the end of politics seems to apply in this case. Although the new ruling class is selected by merit, the question of who gives the test of merit is not without political implications. Once the meritorious oligarchs are selected (or re-selected), how do they reach compromises between each other? The chancellor of power (military) would seem to have a decided advantage. 


\section{Test by Affirmation}

First, resource efficiency is not ignored in the City of the Sun. Communal living and modest habits may have provided some considerable economies. It's huge educational, mystical and military infrastructures, on the other hand were likely to be costly. It is uncertain whether or not the benefit received from them would have been efficiently yielded. Based upon what is described, then, above average marks can be assumed to be earned here.

Second, benefits are distributed to all according to their needs. Those who do not labor earnestly receive only the bare minimum. The advanced classes that afford upward mobility are meted out based on merit. Campanella therefore receives high marks for proportional benefit distribution.

Third, while many factors compose the net positive pressure to produce resources, the City of the Sun seems unlikely to achieve that pressure. It will be recalled that citizens are only required to work four hours per day. The daily ration is not witheld for zero work. Marginal benefit for marginal increase in production is obscured by vague definitions of merit. Less desirable work is rewarded no better than pleasant chores, yet there will be none hungry enough to volunteer for it. Frank Manuel observes, "In answer to the contention that nobody wanted to work and everybody expected his neighbor to do so instead. . [Campanella] responded that love of country supplied the necessary motivation" (Manuel 273). Love of country does not provide motivation on the margin, however. Further, the essential motivator for production throughout $\underline{\mathrm{La} \text { Citta del Sole is }}$ 
principle rather than practical considerations, and there will always be a percentage of the labor pool unimpressed by appeal to principle. Low marks are given here.

Fourth, the status received by the highest administrators correlates more with arcane mystical sciences than with social contentment. The likely needs of administrators are addressed by those sub-administrators below them, who also value mysticism foremost. The system administrators would seem very insular. This seems likely to resemble a bureaucratic model or a school, both of which have difficulty aggressively producing tangible benefits. It is unclear how the system puts a positive pressure on administrators to facilitate social contentment. Therefore, low marks are given here.

Fifth, since the administrators begin by assuming that their science will give them all the right answers, they are unlikely to be responsive to citizens' desires. The administrators seem more like austere abbots than representatives or patricians. The likely discontent the citizens would have about the many experiences they are required to do without would probably have to be ignored, along with other reasonable desires and suggestions. The one hope is that, in such an educational institution, knowledge would flow freely. Aggregation of knowledge at the top (where it presumably already is) seems less likely. Medium to low marks are given here.

Sixth, certainly Campanella's highest value priorities are being enacted first. One wonders whether, under conditions of severe privation, education and social control would give way to food production and military defense. Campanella seems more 
infatuated by the former than the latter. Campanella states that, "Everything was governed by the public, not the private, weal" (Manuel 276). Since the desires are not seen to be coming from the individual actors, low marks are given here.

Seventh, the system's social program requires so much intrusiveness that there are not likely to be any appropriate limits to the system. It is therefore vulnerable to having to expend without limit to overcome all deviations from its agenda, and that is likely to destabilize it at some point. Low marks are given here.

The final evaluation is: two high marks, one medium mark, and four low marks.

\section{Ad Hoc Analysis}

Given that he was such a bright and imaginative man, it is surprising that Campanella's basic design was lifted whole-cloth from his upbringing. The City of the Sun has an unmistakable Roman Catholic character. Its citizens are Dominican monks. Spouses and family are absent. The city is ruled by a high priest. Education, philosophy and mysticism prevail. It seems strange indeed that Campanella could hope for this conception to appeal to a broad audience or be the basis of a hegemonic military power.

One very much has the sense that those citizens not stimulated by the pursuit of scientific knowledge in a monastic setting would be stifled. And while social classes predicated upon wealth have been forbidden, the administrators will have considerable prestige accompanying their authority, although it ostensibly derives from merit rather than inheritance. 
Campanella's design seems to present one of the earliest examples of overly centralized, cumbersome, intrusive communist societies that strip away the products of individuals and repress individually-determined motivations to produce. However, Campanella does not clearly sever the connection between production and consumption. As Negley and Patrick state, "But Campanella's Solarians do not have equal enjoyment of the common property: a minimum of necessities is accorded to all; but beyond that, goods are given to each man not according to his needs, as Marxist theory teaches, but according to his merits" (Negley \& Patrick 315).

Curiously, if there is no private property, what do the meritorious do with the excess they are given? Are they obliged to be gluttons? Do they throw parties to share with whomever they favor? Do they receive excess only if the whole community overproduces, and will the non-meritorious under produce because the minimum ration can be received for nil effort? Wouldn't that nearly ensure a lack of surplus? How will merit be determined if not by productivity? If excess is not allowed to be accumulated, then why be more meritorious than necessary? That would lead to a disincentive to produce, something which no practical society wants, and with which no society can long endure.

Whether or not the City of the Sun would have provided a comparative advantage great enough to have a relatively strong military is unknown. What does seem likely is that a Spartan would beat a Solarian in battle; Spartan soldiers worked more than four hours per day. Sparta was organized to leverage its resources for military excellence, and 
ruled by an elite of generals. One wonders what would keep the military from asserting control in La Citta del Sole?

Individuality and "selfishness" play some role in military affairs. "Selfishness" plays an important practical role in system health. It ensures that the lowest common denominator elements provide for their own needs. How could such selfish instincts ever be removed, socialized or educated away?

The loss of the family is also troubling in terms of individual drives. Nature makes parenting and its attendant attitudes a fairly strong drive in most people. It is easy to be skeptical of a society which raises its young in institutions. Who will put in the extra effort when children's needs are most acute? Will the nursery workers be so transcendent of the community's needs over their own that extra caring is given even without parental bonding? This would be especially difficult in only four hours each day.

What is ultimately troubling about Campanella is his rationale for the citizens' collectivizing at all. Most utopists hold that people would participate because it was effectively, "the best game in town." But the cost at the game may still be prohibitively high. Negley and Patrick acknowledge this when they conclude that, "In an effort to eliminate individualism, selfishness, machiavellianism, and the irrational from his imaginary society, Campanella subordinated everything to the a collective person--the state. . . All work is for the state" (Negley \& Patrick 316). 
It is conceivable that people would sacrifice all individual liberties in the greatest collectivizing crisis imaginable. Prospects of inescapable and society-wide death due to war or privation could perhaps achieve this sacrifice, but would any such set of conditions last? Campanella's organization, and certainly his educational and eugenic plans, are long term, and yet the conditions under which they could conceivably come about are so extreme as render them transitory. Individuals would surely yearn for the things they had forsaken, and seek them when conditions softened. Certainly the stifling characteristics of feudalism and Salem Puritanism led to their disbanding when external conditions stabilized.

While some pursuits of Campanella are laudable, the collectivizing in his utopia seems to be much greater than any likely conditions would merit. Our overall assessment, therefore, must be that it is a system with little hope for sustainable equilibrium. 


\section{Chapter Eleven}

In this chapter Fourier's proposed world of phalansteries (Fourierism) will be examined for the plausibility of its social system.

\section{Fourier and His Phalansteries.}

Francois Marie Charles Fourier, born in 1772, was a French logician and travelling salesman who developed his own theory of human nature. He drafted his views in a series of books. "The initial major formulation of Fourier's doctrine, the Theorie des quatre mouvements et des destinees generales, appeared in 1808. .." (Manuel 641). He published additional elements in le Nouveau Monde industriel in 1827. In these works, he reasoned from his observations of people that they were optimized and most productive when following their natural desires. He classified what he thought those types of desires were, and asserted that the ideal society had the appropriate, proportional and harmonized quantities of each specific personality type (combination and intensities of desires). F.M. Warren states, "Fourier argues that all our passions should be given free rein. ... By allowing them full play they will give rise to higher forms of passion, create new ones, and eventually lead to the perfect state of harmony and happiness" (Warren 56). In this unrepressed state, Fourier believed there were no bad instincts, merely instincts in need of a constructive outlet. A potential murderer in a traditional town would be a butcher in a Fourieristic town. Hence, the ideal community repressed natural desires least, and juxtaposed differing personality types for 
optimum community function. He called these communities "Phalansteries". Frank E.

Manuel explains:

The aims of the phalanstery were the attainment of riches and pleasures; or both could be combined to describe the common goal as the expansive enjoyment of rich pleasures. This would be achieved by uniting pleasures with work, making work attractive, establishing an accord in the distribution of rewards to three 'faculties' (capital, labor, and talent), and spontaneously amalgamating unequal classes. (661)

Fourier suggested a phalanstery's minimum number of inhabitants was 1620 people. This was necessary to balance out at least 810 of the possible personality combinations, although there were an infinite number of potential combinations.

His ambition was for a monarch to sponsor his effort to create experimental communities, which would be composed of hand picked types. "From the very beginning Fourier, like Saint-Simon, was convinced of the imminent acceptance of his projects for the transformation of mankind" (Manuel 645). A monarch sponsored experimental community would prove the superiority of his community plan, and eventually the world would be composed of a multitude of phalansteries, he believed. This would alleviate his great criticism of all previous societies, as Manuel notes:

Fourier's critique of civilization concentrated on the portrayal of its pervasive poverty. Virtually all men--not only the proletariat--are poor, because their passions are unfulfilled, their senses are not appeased, their amorous emotions are curbed, and their naturally complex social sensibilities can find outlets only in pitifully limited channels. As a consequence all men are bored. (654)

Fourier's primary goals were releasing natural drives, harmonizing society, and efficiency (of whatever species). He sought to do this by stimulating people with 
whatever was their pleasure. He sought to elevate them to their highest state of being by fulfilling their individual needs.

So far this seems promising. Fourier makes a connection between unsuccessful pursuit of individual desires and an unsuccessful society. He bases his critique of society upon all previous political systems' failure to harness and allow for the individual's drives. While that is at best a gross rhetorical exaggeration, the sentiment clearly states that a system which too greatly hinders the pursuit of individual fulfillment stifles its own base of power.

Fourier suggests this stifling environment is also responsible for producing the negative expressions of human nature to be found in traditional civilization. As Jonathan Beecher explains:

[Fourier] believed that he had discovered the natural form of social organization. He had designed a set of institutions that was consistent with the full expression of man's nature, thereby freeing him from the subjection to external authority and removing the principal cause for criminal or other antisocial behavior. (253)

So, Fourier's critique acknowledges the value of individuals pursuing fulfillment. In it he places specific blame on the existing "pitifully limited channels"(ibid 654) to pursue fulfillment. What then can be said of Fourier's proposed political system?

\section{Testing by Abnegation}

Fourier suffered from the fallacy of homogeneity in a bizarre way. While his whole theory was predicated upon the belief that there were many diverse types of 
people, he spent an inordinate amount of time in detailing solutions to sexual dissatisfactions. It is doubtful that most people want their social system to proscribe sexual conduct in so many personal situations.

Fourier further suffered from the fallacy of free transition. He seemed to believe that a phalanstery could be brought about by monarchical decree. He therefore glossed over the amount of exhortation that would be required to select and indoctrinate 1600 people at a time into a closed community. Further, the community would have to be a fully functional "going concern" lest his phalansterists' needs be frustrated.

Fourier also suffered from the fallacy of baseless extrapolation. The economy of his community was driven by supply, not demand, since people produced what they were suited to produce, rather than what others were interested in consuming. Thus, he assumed that the economy would thrive as traditional "boring" economies did, but there was no basis to that logic. Equilibrium would surely be unchecked.

Next, Fourier suffered from the fallacy of the end of politics. He assumed that completely-sated individuals would be neither greedy nor domineering. Since it is questionable that their satiety would be complete, his conclusion has no support. Further, what of those individuals for whom it is their nature to control? Would they not create dissatisfaction by inhibiting the pursuit of desires of the rest of the actors?

Fourier suffers additionally from the fallacy of static contentment. This thesis has already given preference to Abraham Maslow's explanation of human nature over a scheme such as Fourier's. The salient difference between the two is that Fourier assumes 
people are of immutable "types," and so can be satisfied by similar conditions indefinitely, whereas Maslow holds that needs evolve as the individual grows. While Fourier approves of his phalansterists pursuing diverse passions, their "place" requires them to be of a predictable inclination to give the whole system its "harmony".

Finally, Fourier suffers from the fallacy of the last move. He assumes that his social design is the last one that will be needed. He also assumes that other social systems will eventually split into more phalansteries, rather than preying upon other phalansteries, or reconfiguring themselves to take advantage of opportunities to do so.

\section{Testing by Affirmation}

First, Fourier pursues efficiency in as many forms as he can construe. While he loses marks for the huge numbers of edicts and proscriptions his phalansterists must adhere to (and the likely cost of social control that would result), his general emphasis on efficiency might bear some fruit. High marks are given here.

Second, Fourier essentially offers a self-serve set of benefits. The benefit of being a phalansterist is that you need have few inhibitions. There is also a certain amount of communal sharing of goods that equates with benefit distribution. Medium marks are given.

Third, Fourier's greatest claim, compared to conventional societies, is that his phalansterists would be much more productive because they would so enjoy what they do. The validity of his particular typology of human personalities aside, Fourier's 
economy seems almost anarchical. Since it is driven by what producers want to produce, not what consumers want to consume, who will buy the goods produced, and what will the producers use to purchase more raw materials? This is almost an anarchistic command economy. The waste and lack of customers would surely be frustrating, perhaps even stifling "non-bored" phalansterist workers. Medium marks are given.

For the fourth point, the same comments apply. Medium marks are given.

Fifth, Fourier's aggregation of individual desires is based upon his faith in his topologies of human desires, and not on a flexible form of representation or government. Since harmony is mandated centrally, there seems little room for live feedback, and real data controverting the typology. Low marks are given.

Sixth, Fourier creates a way of life, but very little government. Once his community is set in motion, the odds are that very little will be enacted by the collective at all. Low marks are therefore, given.

Seventh, Fourier, like many theorists propping up inexact hypotheses, would add patches and supplements to his system indefinitely. Consequently, there were no true limits to his system. The system was obliged to do anything necessary to prop itself up and vindicate Fourier's name. It proscribed behaviors in so many contexts at so many levels that would be nearly impossible to enforce, that the system was without a clear conception of its limits. Low marks are given.

The final score is one high, three medium, and three low. 


\section{Ad Hoc Analysis}

The primary difficulty with Fourier is his desire to let all pursue their wants, and yet harmonize society. While on the face of it his is an extremely individualistic society, Fourier depends for his harmony on a plentitude of proscriptions and slogans to be adhered to. There is considerable tension between these two poles. He asserts that people can be left to their own direction, and yet he writes thousands of pages on how they should interact, how they should coerce each other, how they should be categorized for work, how special projects should be done, how they should not marry, how phalansteries should be given incentives to work together, how children should be coaxed to shovel manure, how houses and hotels and civic halls and baths should be architected, and literally hundreds of variations on sexual ethics.

Fourier, who bandied phrases about perfectly balancing natural tendencies, expected people to arrange themselves in idylically choreographed and convenient groups. If these tendencies are inherent, why then do communities left unto themselves not seek out such an equilibrium? If people knew in which small town there was a place especially intended for them to occupy, would they be pleased? What if they desired a "better" place? Would their departure unbalance the phalanstery?

Fourier's advice to individuals may be summarized as one of encouraging their natural tendencies. He is perhaps what Freud would have been, had Freud wanted to design worlds. They both attempted to precisely depict human nature in rationalist terms, and draw conclusions from those postulates. How such characteristics could be measured 
and compared is a challenge. Adjusting the phalansteries if such characteristics changed over time is another. What should be done if nature does not produce the proper ratio of each personality type is another. Ultimately, getting people to agree to cede their right to free association is the greatest difficulty in his proposal.

Fourier bases the stability of a program--potentially global--on his convoluted and always growing theory. As to the validity of his theories, our most appropriate retort should be to remember Occam's razor: All other things being equal, the simpler theory is more likely to be correct.

It is difficult to take all of what Fourier says as representing his literal intent. Fourier fought his own credibility at times. He was, from a variety of reports, deeply suspicious of philosophers, religious authorities, and cosmopolitans seeking to squelch his movement. Manuel confirms, "He [Fourier] showed mild symptoms of paranoia" (Manuel 642). He thus put into his work artifice, deceit and misdirection to diffuse possible resistance. His writings attacked the institutions family and prevailing economic systems, but he paid lip-service them by at times supporting both.

Fourier lived long enough to see and comment on several attempts to enact his social design. He was by most reports more of a hindrance than an asset. He criticized the communes venomously and relentlessly, complaining that they failed to properly implement his ideas.

In the United States, several Fourieristic communities were formed. According to Raymond Muncy, "Fourieristic societies attempted to maintain that uneasy balance 
between collectivism and individualism but were unable to do so. Private inte ests were too powerful to be indefinitely sublimated to communal interests. . . the Fourieristic associations [survived on an average] three and a half years. .." (Muncy 48). Fourier's explanation of human nature fails the test of Occam's razor; when all else is equal, the more simple theory is probably right. Fourier's theory was anything but simple, and by this logic Fourier was anything but right. 
Chapter Twelve

In this chapter Bellamy's Looking Backward will be examined for the plausibility of its social system.

\section{Bellamy's Looking Backward}

Looking Backward was published in 1884, and followed by Equality in 1887. Taken as a whole, they represent Edward Bellamy's utopian vision, which has been widely read since. An attorney and then novelist, his books made him a celebrity. Bellamy's sets for the Bostonians of 2000 the goals of social and economic equality, human solidarity, order, and the opportunity for self development.

He sought to achieve these by creating an "industrial army." Jean Pfaelzer explains, "Bellamy, who had always wanted a career in the military, presents the utopian army as a practical agency for the organization and education of an ideal society" (34). Universal participation would be achieved through conscription. Fair and appropriate careers would be received through job assignment. Since all would work for the army, and all would be paid by the army, there would be no economic elites to abuse power. His industrial army would provide for material needs. A result of this would be to remove economic necessity from the motivations for marriage, and therefore Bellamy believed that marriage would be based solely on love.

Bellamy seems to believe that people can be patriotically and universally united in armies, regardless of class, ethnicity, race and gender. He assumes that this is the 
structure of a military social system. Negley and Patrick detail Bellamy's thought process, "The military of all our institutions, is the one which has consistently achieved the highest degree of institutionalization; that is, it has more effectively subordinated and eliminated all individual values to the purposes of the institution" (Negley \& Patrick 77).

Bellamy proposed to remedy hardships of his era. Elisabeth Hansot notes, "In contrast to the ferocious competitive system of the nineteenth century, Bellamy's utopian society is organized to ensure solidarity through economic equality" (Hansot 136). Bellamy believed this would work because of his benevolent concept of human nature. According to Negley and Patrick, "He [Bellamy] believed men were essentially and fundamentally good, and that the inadequacies and evil observable in the actions of men were directly attributable to the inefficient and inequitable institutional structures of their society" (Negley \& Patrick 77). Thus Bellamy reasoned that if inefficient and inequitable societal structures could be replaced, then peaceful human solidarity could be achieved. Boston in the year 2000 would be run by senior officers in the industrial army. A sufficient ration would be accorded to all. Bellamy sought above all to replace mercurial motivations with socially constructive ones of patriotism and the prestige of contest prizes (usually ribbons).

Bellamy had a particularly progressive attitude towards education. In one passage, Bellamy has Dr. Leete, the protagonist's guide to New Boston, state:

There are three main grounds on which our educational system rests: first, the right of every man to the completest education the nation can give him on his own account, as necessary to his enjoyment of himself; second, the right of his fellow- 
citizens to have him educated, as necessary to their enjoyment of his society; third, the right of the unborn to be guaranteed an intelligent and refined parentage. (Bellamy 181)

And yet he does not develop this avenue for change as one might expect. Elisabeth Hansot observes, "Aside from exposing and reforming nineteenth-century malpractices, the treatment of education is astonishingly scant when one considers what a fertile field malleable human nature offers an enterprising utopian author" (Hansot 120). Bellamy, who criticizes nineteenth century education mostly on economic grounds, seems comfortable that education in the year 2000 need not improve on human nature.

\section{Test by Abnegation}

Bellamy would suffer from the fallacy of static contentment. Bostonians might be thrilled with all the bread and blue ribbons they can eat just after a famine, but what happens after tastes change? Bellamy's system is configured only to serve material survival needs, and certain social ideals.

Bellamy would also suffer the fallacy of homogeneity by assuming that all citizens will be sufficiently motivated by patriotism and prestige. Almost certainly a given percentage will simply have different motivations.

Bellamy would further suffer from the fallacy of baseless extrapolation. He assumes that what works for a martial army conscripting a fraction of the populace would also work for an industrial army conscripting the whole population. 
Bellamy would in addition suffer from the fallacy of fo:tunate oversight. He desires enough technology to keep population well cared for, but wants a low-density non-industrialized village. Where would the technological base come from?

Finally, Bellamy would suffer from the fallacy of the end of politics. He offers little or no reason why politics would disappear in his polity, yet he cannot accommodate the selfishness or cynicism that would go with it. Bellamy appoints industrial officers to administer the government, but has nominal recourse if they abuse their power, or are pressured to favor particular cleavages. What if a guild, like a political party came to dominate the government? Would they be motivated to continue sharing in solidarity?

\section{Test by Affirmation}

First, Bellamy creates a large bureaucracy to handle job selection, training, and administration of the industrial army. Few armies can accurately be described as financially efficient. Low marks are given.

Second, benefit distribution is quite proportional. High marks are given.

Third, Bellamy saps actors' motivation to produce resources by removing the correlation between production and reward. The army bureaucratizes decisions, and removes the potential reward for taking risk, thus removing entrepreneurial activity from the economy. As Elisabeth Hansot puts it, "Bellamy's incentives are, on the whole, not very convincing. A man motivated solely by a red badge is either playing games or not motivated at all" (Hansot 137). Low marks are given. 
Fourth, the commanders in the industrial army who act as system administrators have little direct connection to, or dependence on, grass roots actors to retain their status. The prospect of positive pressure arising for the creation of social goods is low. Low marks are given.

Fifth, the officers in the industrial army have no device for obtaining feedback from the population. Rank does not imply necessary awareness of the needs and desires of others. The absence of a feedback loop constitutes low marks.

Sixth, without the officers described above, only universal wants can be addressed. Medium marks are given.

Seventh, Bellamy did not believe that his system could be harmful and therefore did not limit it. Low marks are given.

Bellamy's final score is: one high, one medium, five low.

\section{Ad Hoc Analysis}

Many of Bellamy's instruments and goals will be irrelevant in actual application. For example, it is easier to administer stability than freedom. Therefore, while the army may try to encourage freedom, it will restrain more freedom in the name of order than it creates. Most of the details involved in Bellamy's economic blueprint require citizens to join in lock-step without recourse. Individuals must choose a career at a young age, and industrial careers are given a decided political advantage. Once in a career, Bellamy leaves little doubt that a corporal or a private in the industrial army is subject to austere 
discipline. Yet in the face of these constraints, Bellamy assumes his citizens will be sanguine. As Negley and Patrick view it, "He [Bellamy] did not consider the ordering of institutions according to his economic policy to imply a system of controls and restrictions on the individual, however naive his belief may appear to us" (Negley \& Patrick 79).

To prevent the natural imbalances of Bellamy's command economy, he adds layer upon layer of structure to prop up the system.

Bellamy's society further suffers from the classic Marxist conundrum of how to motivate people to be productive, without a correlation between production and consumption. Also, consumption must be checked by rationing and production must be spurred by social pressure. This social pressure is an imbalanced system of its own, and probably has poor leverage to reach the mass of humanity. After all, what is the product of those applying the pressure? They are merely "managing" someone else, and so are dependent on the productivity of that person for their worth. If average productivity is low, then the solution typically suggested is to add more social pressure, but that only increases the number of persons depending upon someone else's productivity for their worth. The cycle will crash at its extreme.

The entire existence in Bellamy does not seem to "go anywhere". The society seems to perpetually keep clean and calm, but are their any challenges? Is there any desire to extend the limits of human endeavor? Do Bellamy's citizens strive? Elisabeth Hansot states, "Human nature is static in Bellamy's future society because the one ideal it 
expresses is derived from the inadequacies of the past--a past that no longer exists to the extent that it no longer has meaning for the inhabitants of utopia" (Hansot 134). A social system that relies upon an external place or time is dependant upon that reference for definition of it identity. When that reference is blurred or forgotten, so too is the identity. A new defining reference with current relevance will inexorably be sought, lest the community crumble.

There is great concern about the accountability of leadership in "New Boston." How is a guildmaster to act in any way other than as a partisan activist for his or her guild? When dealing with underlings, what is to temper his considerable authority? Who is responsible to the individual? What is to stop oligarchy? What are the limits of the state? Do leaders need that much power to administer the system? What checks and balances exist to prevent corruption and abuse by the industrial army? Without a disincentive to abuse the system on the margin, there is insufficient balance in the system.

A classic difficulty of bureaucracies is that they give poor incentives to produce. Bellamy's philosophy offers fraternal behavioral guidelines, but little practicality. It requires the system to enforce it. But the system will require its own power base, guidelines and incentives. Poor, slow and cumbersome are functioning is likely. What if everyone thinks that someone else will produce surplus? Not all people are subject to positive social stimuli. 
In Bellamy's era, almost any collectivizing was difficult, so imagining a trickle was just as difficult to imagine as a deluge. Negley and Patrick note that:

In a period of almost unrestrained individualism, free enterprise, and "the less government the better" politics, utopists were anticipating the "welfare state", the nationalization of industries, "socialized" medicine and health programs, unemployment insurance, old-age pensions, and numerous other such proposals which were frantically "radical", "dangerous," or "preposterous" in the latter nineteenth century, but which in 1950 have become a part of every man's political vocabulary. (16)

This may begin to explain why Bellamy's imaginings heaped large government element upon element. So too, this may explain why Bellamy did not see this as a threat to liberty. He had no experience that could begin to let him sense what the tradeoffs would probably be.

\section{A Special Note About the Industrial Army}

The notion of a military organization to accomplish an economic agenda gives pause for several reasons. Obedience may be high in the military, but it is not absolute. The organization's objective may have as much to do with it as the structure.

Commanders in the military have rank, but they also have guns. The price of not being effective or following orders in the military could be mortal.

The military social system does not and cannot exist as the largest social system. Armies are supported by producers for which the army works and provides a service. Armies are collectivized by a common external threat. Armies are not composed of $100 \%$ of the citizenry and therefore do not validate a theory of 100 percent mandatory 20 
year conscription. Resistance to participation when 20 years is at stake would be considerable. The weight carried by nonconformists would be greater the longer the conscription term.

Armies are also poorly suited to create wealth because armies collectivize and institutionalize risk. Where does an entrepreneur obtain resources and receive reward for exceptional effort and unlikely success? Risk taking would not be tangibly rewarded for the pragmatic, and hence would not be undertaken. . . nor would its proceeds.

Armies are also poorly suited to respond to grass-roots needs. By definition, they are organized to apply great resources to unpleasant tasks. Armies are not used accustomed to asking the privates how they feel about the direction the commanders are going. Military governments, not beholden to civilian leaders who in turn are beholden to citizen voters, are notorious for ending up in corruption.

Armies use life and death motivations and punishments to entreat and compel compliance. Industrial collectives wielding only ostracism to compel and esteem to entice would not be able to motivate large factions of the general populace.

Armies don't just offer prestige; armies offer safety when the war is won and troops get to go home. This motivates the members to contribute and comply. Bellamy only motivates with the carrots of a few social incentives, and theses are of a rarified variety that appeal especially to people with his sensibilities.

Jusi as Freud seemed to think sex was an ultimate motivator, Bellamy seems to think esteem to be the ultimate motivator, and perhaps it was for Bellamy. Certainly he 
received enough attention for his better-mouse-trap. Above all, as Negley and Patrick conclude, "Stripped of its romance and humanitarian language, Bellamy's social philosophy is plain economic materialism" (77). 
Chapter Thirteen

In this chapter Wells' $\underline{A}$ Modern Utopia will be examined for the plausibility of its social system.

\section{Wells' A Modern Utopia}

H.G. Wells was a British author and futurist of considerable renown in the early Twentieth century. He stands with Jules Verne as one of the founding fathers of science fiction. While he oscillated between optimism and pessimism over the course of his career, A Modern Utopia is generally considered to a balanced work. Elisabeth Hansot notes, "When Wells wrote A Modern Utopia in 1905, he was still confident that men could lead better lives if they could only escape from the deadening restraints of outmoded religious beliefs, moral conventions, and social shibboleths" (Hansot 146).

Wells wanted to contrast his proposal with the flaws of previous utopists. He emphasized adaptability, plausibility, and dynamism and wanted to design a utopia that, more so than any previous one, could truly be achieved. Perhaps because he was a skilled story writer, he wanted his utopia to appear to have a history and deal with its problems. This, combined with his solid scientific grasp, added to plausibility of his designs. As Negley and Patrick state:

Wells was perhaps the most aggressively progressive of all utopists. He was not naively optimistic about the future of man and society, but he staunchly maintained that any development toward the achievement of the ideal social structure could be brought about only by the employment of scientific methods of social organization. (226) 
Wells' economic system relied upon nationalization of all energy producing sectors and commercializable land. The energy would be sold and the lands leased to finance the welfare system and other operations of the government. Wells extols, "The trend of modern thought is entirely against private property in land or natural objects or products, and in Utopia these things will be the inalienable property of the World State" (Wells 96). Private property was still a very real part of Wells' scheme. However, he limited it to personal possessions, sentimental or necessary equipment, and partnerships in business ventures. He was emphatic that in his utopia wealth would not afford a merchant power. He says, "Here there is no private fortune in the whole world that is more than a little thing beside the wealth of the State. The samurai control the State, and by their vows they may not avail themselves of any of the coarser pleasures wealth can still buy. Where, then, is the power of your wealthy man?" (Wells 289 ).

Wells determined that an exceilent society required excellent administrators. His was lead by a class of elites, called Samurai, who were either highly creative or highly pragmatic. The requirements for joining the elite were passing exams to demonstrate excellence, and a willingness to lead a nominally temperate life. Samurai were expected to be tolerant of diversity, mildly socialist, and place an emphasis on education.

To receive the full benefit of these highly talented leaders, authority had to be centralized, "Centralization is for him [Wells] the keynote of efficiency for the future society, and he recognized from the beginning that nothing less than world centralization would suffice" (Negley \& Patrick 227). 
Wells expected that those seeking to avoid participating in his plan would decrease its efficiency and undermine its programs so, for him, universal participation was mandatory. For example, by practicing eugenics he expected to eliminate the dysfunctional. The base and the dull were not allowed to reproduce. He justified this as best for society in a utilitarian sense, and assumed it would be good for the evolution of the society; both by motivating citizens to prove their worth, and by weeding out those that do not.

Wells did not require a fundamental change in the nature of man to bring about his society; he designed it with the men of his time in mind. In contrast to many previous utopians, Wells claimed he was not seeking to change the nature of individuals: "Nor did Wells display the naivete which anticipated a transformation of man by the mere achievement of economic equality; economic adjustment was but one of the numerous important problems of social organization which must be resolved by scientific control" (Negley \& Patrick 227).

To ensure that his Modern Utopia could not be accused of being perpetually static, Wells geared it to generate innovation and support creativity. The creative ranks of the Samurai were expected to continuously turn out better mouse-traps which would in turn be built and implemented by the pragmatic ranks of the Samurai. This was also in response to his distaste for the plodding, boring governments of his day. Wells made creativity the unique element of his utopia, elevating it to the status of a cure-all. This would allow his utopia to optimize and adapt to whatever new possibilities came along. 


\section{Test By Abnegation}

Wells conspicuously avoids the fallacies of homogeneity and static contentment, but suffers from the fallacy of the end politics. Samurai will vie for supremacy, undercutting each other (the "creatives" will probably lose the influence needed to get reforms enacted), and his plans will cease to be scientifically implemented. Further, some plans may disadvantage some cleavages so intensely that they refuse them whatever the cost (e.g., the eugenics program).

Wells also suffers from the fallacy of the last move. Although he designs a society to generate creative ideas, there is no sense that these are allowed to tamper with the structure of the society itself. Even as he bows to the altar of innovation, Wells hopes he has created the last innovation to be enacted.

Wells demonstrate the fallacy of fortunate oversight. By what instruments would the Samurai control the implementers of the policy? The likely army would have to have some form of loyalty, and would have to be willing to suppress people all the world over. The pressures for schism and revolt would be tremendous.

Wells also clearly suffers from the fallacy of the end of politics. His samurai are to be the best and the brightest, but they are not to be ambitious. They are not to represent parties or interests. They are not to act as advocates. These traits, Wells would have us believe, are kept away by the temperate life these elites undertake. This is a far cry from Wells' statement that he will populate his utopia with men like those he would find in England in his day. Also, this would create a lack of representation and 
vocalization of the needs of the grass roots. Hansot affirms this when she says, "[Wells] sketches an outline for utopia's political structure, but he does not provide for the disagreements or the inadvertent disorders that make a political structure more than a mechanism for recording consensus" (Hansot 158).

\section{Test by Affirmation}

First, Wells' Samurai can be expected to be efficient. However, his extensive social agenda, carried out universally, and implemented with a zero-tolerance for noncompliance would run into so many forms of diminishing returns as to render it phenomenally inefficient. Some of this might be reduced if Wells agenda were enforced ruthlessly, but even at that the police state required would seem necessarily immense. Low marks are given here.

Second, Wells' quasi-socialist agenda would have widespread distribution of resources. High marks are given here.

Third, Wells' population would probably be no less motivated than Stalin's was in the early 1950 's, assuming the Modern Utopia rose to prevent society from going over the brink. Medium to low marks are given here.

Fourth, the Samurai appear much too insular and with too many tools of influence at their disposal to be held accountable. Low marks are given here. 
Fifth, the Samurai would have a scientific interest in public opinion, but no automatic and proportionately-weighted mechanism to measure it. Medium marks are given here.

Sixth, the Samurai would enact the highest value practical goals for the system, not the subjectively most important goals of the grass-roots actors. Low marks are therefore given.

Seventh, the system is imbalanced between the powerful and the powerless, between the social plans and the production necessary to fund them, between the social norms and the practical policies of the administrators who will serve the system because it services them, rather than the subjects who support the system. Low marks are given here.

Wells' final score is: two medium, five low.

\section{Ad Hoc Analysis}

Wells exhibits a paradox in his innovation-producing engine. He asserts that innovation is valuable, but never delivers a criterion by which to judge innovation, nor a value to it that is innate. Hansot dissects this problem adroitly, saying:

The minimum content that can be given to Wells's ideal of creativity is a social content; the degree to which innovation can shape or influence the future of the species is the criterion for its success. Although only what is "valuable" will be successful, Wells offers no independent criterion of value, and when he makes posterity the judge of what is valuable in the present, the effort to find a criterion collapses entirely. (153) 
The value of innovation is always to future generations, to posterity. The formula is to innovate now, and success will be based on the future acceptance. But there is no movement of capital or reward backwards in time in Wells' plan. Since now is never the future, reward is never appropriate and change will not be stimulated. Well's engine therefore has a fallacy; an infinite regression.

Wells doesn't seem to want change after his stage of innovation, in any event. The Samurai optimize rather than revolutionize. Further, since they select their own members, and all candidates come from within their world-wide-society, there is no external vantage point for creating new systems. The system seems to assume that it is the last system.

Also of concern are some assumptions about the ability of the Samurai to go unchallenged. Wells assumes that all talent will be coopted by the elite. This certainly does not hold true today.

Wells' eugenics plan assumes that intellect is the only valuable human quality. What about determination? What about compassion? What do the base and dull think of this plan? Couldn't they love children and want to raise them too?

Wells, viewed society in a biological framework, much like Charles Darwin and the entire family of Huxleys--some of the great thinkers of his era. He went to great lengths to emphasize this science was for the benefit of the individual. However, the eugenics Wells endorses are for the benefit of individuals collectively, perhaps, but not for those specific individuals denied the right to parenting. Julian Huxley, accepted the 
scientific premise but changed the conclusions 40 years later when, as the first Director General of Unesco, he optimistically stated:

Our evolutionary analysis shows clearly enough that a well-developed human individual is the highest product of evolution to date. This provides external and scientific support for the democratic principle of the dignity of men. . . It also constitutes a complete disproof of all theses, like those of Hegelian philosophy, of fascism, which maintain that the state is in some way higher than the individual, and that the individual exists only or primarily for the state. (41)

Wells will probably fail to get rid of bland, uncreative government. He assumed that if innovative individualists were in charge, then dynamism would increase. This is not a necessary outcome, however. What if boring government is what works best when generalized for the lowest common denominator?

Wells' whole explanation of the value of creativity is too simple. This is a characteristic flaw of single factor analysis. Change for change's sake serves no purpose. Creativity needs guidelines by which to be judged. For example, Dadaists may be creative, but form does not follow function in their art. Wells needs additional criteria by which to judge creative ideas. Once other guidelines are in place, appropriate value judgements must be made. Considerations such as efficiency, feasibility, reliability and legitimacy become very important. Then the pragmatic Samurai will hold sway.

Ultimately one wonders how Wells' values are any different from the status quo. Pragmatists would return to compromises and averages and administrators would do what advantaged themselves. 
In terms of his administrators' namesakes, the Japanese Samurai, Wells seems to mischaracterize them. Samurai were not mandarins. Samurai in Japan ruled because they had power of steel and social position accordingly. Science was not their tool of management. They had tyrannical power over those below them, and were obliged to be wholly obedient to their superiors in a feudal arrangement.

The stereotypical creative person today is often regarded as a "harmless cuckoo" who can dabble in a many different directions because "this hurts no one." No instability is created by change for the sake of change. Like writers of fiction, many are ignored by the mass population because they are no better than the rest. It seems that "creatives" would be poorly positioned to play power games in Well's Modern Utopia. The "pragmatics" playing for tangible stakes, could affect real events, whereas the "creatives" have no monopolies--no desmains--with which to leverage other players, so why would the "pragmatics" yield them any influence? Unless, like the mandarin political strategists who attached themselves to generals powerful enough to enact strategies, in a fiercely competitive environment, the "pragmatics" could ostensibly ignore the "creatives" and perpetuate a stable status quo. As Negley and Patrick conclude:

... it is difficult to quiet the suspicion that Wells too indulges in the assumption so common to utopian thought, that men of intelligence and scientific training. . . will, when vested with the power to control the social order, evidence the good will and benevolence necessary to make the exercise of that power a benefit rather than a debacle. (227) 


\section{Means and Ends. . .}

Allow creativity to build a better society when myriad system components must be reinvented, but do not hold off on the implementation of those better systems because the creative type might dream up a more optimized version next week. Wells' is a society leveraged to optimize change, but not ever intended to benefit from it by actually changing.

It is practical to ask in Wells' system who gauges what is the appropriate level of creativity for gaining entrance into the elite? What are the tests to determine that level of creativity? Do the "creatives" develop an elaborate test, which they administer, and are only credentialed creative persons allowed to consult in the creative functions of administration?

What if a new category of creativity develops that the old-guard-long-haired are slow to acknowledge? Institutionalizing creativity seems to guarantee a level of social acceptance that most lone-inventors would love to have. But it seems that there is an aspect of being outside something that allows one to develop truly different approaches. That may be lost in the context Wells would like to create.

How do you institutionalize rebellion? Certainly Mao Tse-Tung could not, and he was one of the more successful Mandarins in China's 3000 year history. Wells may allow more freedom, but implementing some of the planks of his platform would almost surely require repression. It is difficult to encourage individuality and freedom, and yet absolutely control so great a portion of people's lives. 
Wells' science is on murky ground at times. Geneticists suggest that it may take thousands of generations of selective breeding to remove a single trait. Wells may have a difficult row to hoe with his eugenics to remove base and dull people from the gene pool. And even if he did, what then? There will still be people with IQ's in the lowest ten percent. They may be more measurably intelligent than individuals in preceding centuries, but is that marginal gain worth the marginal cost?

On the whole, Wells seems to have a draconian view of what would be required to have a perfect society. For individuals to accept this, the spate of potential ills from which a world a world government would have to provide protection would have to be intense, immediate, pervasive and persistent. Wells himself makes such allowances: ". . . he [Wells] seems prepared to concede that this happy state of affairs is not likely to be brought about until the increasing devastation of world wars has by attrition left men the alternatives of scientific management or barbarism" (Negley \& Patrick 227).

That seems unlikely, given the desire of people to survive by avoiding world wars. But, perhaps Wells' predictions would come true if an even larger conflict were to occur. . perhaps a war of the worlds. 
Chapter Fourteen

In this chapter we will summarize the lessons learned about measuring Utopias in terms of system performance. It will be a summary of utopists' views/lessons

learned/generalizations about measuring utopias in terms of system performance.

It is telling that rational utopists believe that modern tools will enable a centralized government to control its citizens. This is seen in almost every centralized non-religious based utopia. The absolute debunking of this assumption comes when one realizes that modern tools will also be available to those wishing to rebel. It is the fallacy of fractured equilibrium to assume otherwise. Economies of scale create surplus that can be used for harmony or for struggle. Computers digest information that can be used for organization or subversion. Global communication and transportation can spread revolutionary beliefs as well as homogenous beliefs.

\section{Against Single-Factor Analysis}

The perfect society is not optimized for one social class, faction or aesthetic value. Nor are individuals discouraged or disincentivised to seek and work for their own fulfillment and advancement. Society must contain multiple strata that individuals may strive for or slide to depending upon the efficacy of their states of mind and practices.

According to Leclerc, "The role of the imagination is to come up with new models, better adapted than existing ones to the individual's changing needs. Reason 
must test these visions and put into action those that are viable" (Leclerc 40). Utopian thinking serves its purpose. It advances imagination on the subject of how to meet individual needs. Utopian literature is read by individuals, to be implemented in their own lives by individuals. It is perhaps only utopists themselves who misunderstand this when they expect their literature to result in centralized, choreographed and authoritarian programs. To continue the metaphor, it is each individual dancer who determines his or her steps, and the utopist has primarily just shown them some alternatives they may wish to employ. Utopianism is at its best when it avoids the pitfalls of single-factor analysis.

Utopias as a class tend to be closed to criticism. Perhaps because the authors hope to have already perfectly optimized their systems, they resist review by peers. As Stephens notes:

The most common criticism of Utopian writing are that Utopias are in the main both static and unrealistic. But I think a further significant criticism could well be that they are deceptive in terms of the values they communicate. The orthodox, positive Utopias set out to sell their worlds to the reader as wholly desirable, but in doing so they all too often block off any dimension of self-criticism in the text, particularly where they are fully self-consistent. (10)

Even if it were perfect, how can this be revealed without thorough review?

Individual desires will change in time, and so too do utopias need to be able to change, but this is seldom seriously accounted for by utopists. "In a very real sense, the Utopian imagination is caught out again and again defending its implicit status as author of the last conceivable revolution, a position which history makes untenable as a matter of course" (Stephens 10). 
Utopists pursue perfection, but want to decree the standards by which their work should be judged. While this is problematic because it invites bias, the error goes further. It also ignores the purpose of academic inquiry: to reveal truth.

Perfection means an optimum, and an optimum must be determined or measured in terms of a standard. Whether it is the optimum amount of sunshine to allow corn to grow fastest; the optimum amount of food to eat to be nourished, but not gain weight; the optimum amount of taxes to pay to get significant service, but not be overly burdened; or the optimum number of children to have, optimums require a context.

All optimums are in reference to at least one criterion, but ultimately this relates to individual satisfaction with what results from them. The optimum amount of food depends upon which criterion is prioritized: aesthetics of taste, long term cardiovascular health, desire to be svelte, desire to have a bodily reserve in a famine and others. The optimum number of children to have depends upon which criteria are emphasized: interest in parenting, financial resources, interests competing for a parent's time, health considerations for the mother, population pressures in society and others.

Many utopists select criteria that reflects their preference and generalize from it. This cannot be considered optimum. Participants in the system are too diverse for a single point of view to be used to judge myriad preferences to assess what is subjectively optimum. In the absence of an horrifically collectivizing external event (arctic winter, war with no retreat, etc.), individuals do not happily subjugate their preferences about personal issues to the social system. 
Even communes that compose themselves with apparently uniform participants often have this problem. The communes are seldom defined only in terms of what they are, but in terms of what they are not--the outside world. When a generation has passed, the new blood judges again and has no common distaste for the outside world, hence they move on to return to it.

Perfection may be sought, and perhaps achieved for a moment. As Molnar reminds us, "The truth is that society is always unfinished, always in motion, and its key problems can never be solved by social engineering. Yet, man must conquer, again and again, the freedom to see this truth."(Molnar iv).

The solution is to understand the driving force of systems is the individual actor seeking what he or she desires,'

Individuals are changing, breathing, diverse, autonomous actors with immediate desires relating to their perceptive sense of being. They have the direct stimulation to provide for their own needs, and to adjudicate which nerds can reasonably be met, in what order their needs should be approached, and which needs should be deferred due to implausibility or excessive cost. That is quite a lot of information, and much of it is inconstant because of the changing landscape around the individual and the changing way in which the individual "sees" it.

Individuals must be committed to a system for it to have a hope of success. Rosabeth Kanter's typology of social commitment factors discussed in Chapter Five 
highlight a consistent weakness of utopian works. Her typology includes continuance, cohesion, and control commitment. Continuance is strengthened by requiring investment and sacrifice from actors for access to benefits. Cohesion is strengthened by requiring communion with fellow system members and renunciation of competing systems (like patriotism). Control commitment is strengthened by facilitating the mortification of individual priorities and the transcendence of group values above individual values. It is apparent that very few works of utopian literature include more than communion and transcendence. Communion is plentiful as we saw in Bellamy and Campanella's works. Fourier and Wells had precious little of even that. The transcendence which was alluded to (or what would have been termed transcendence had Kanter's typology then existed) by all the utopists was seldom well-explained. The Solarians, Bostonians, Phalansterists, and Modernists simply sacrificed for the good of the whole, ahead of themselves. Except that these systems were so generous in the nourishing of the citizens' wants, the reader does not know why the utopists expected group-values to esteemed above individual values. Rich in clinical detail but wanting in emotional story-line, the works of most utopists show their authors' desire for the advantages of strong commitment in their polities, but demonstrate little feel for the actual formation of commitment within these groups. 


\section{Chapter Fifteen}

This chapter summarizes insights derived in previous chapters as they pertain to creating viable and desirable social systems.

\section{Conclusions About Some Existing Systems}

Federalist democracy in a middle class society is a good compromise. A constitution with a balance of powers and limited spheres of responsibility is a good idea. Free flow of information and freedom to associate with whomever one chooses are good ideas. Preserving citizens' need to provide for themselves is a good idea. Preserving elites' accountability to citizens is a good idea. Easily administered taxes are preferable. Minimizing laws that inhibit the pursuit of happiness is a good idea. Polities with a shared history which struggled to form and which have similar overriding values will show commitment to their group, lending resiliency to their social system.

\section{Natural Counterpressures to Extreme Centralization}

There are many desires and realities which act as a natural counterpressure to extreme centralization. The desire of individuals to retain what they produce is one of these. The desire of local elites to collect resources and power contributes as well. It seems to be a statistical certainty that the larger a sample is, the smaller the number of common denominators must be. This lack of commonality decreases the efficacy of extreme centralization. The inefficiency of transporting and administrating the collection 
of resources and opinions over large areas stimulates local actors to retain and utilize resources locally. Information tends to become less accurate the more it is aggregated; thus a wisely designed system utilizes most information near where it is collected. Individual autonomy is necessary to achieve individual fulfillment. If it were only a question of logistics, this could be seen to be so. Desires become increasingly idiosyncratic as they climb up Maslow's hierarchy of needs, and thus inaccessible to centralized ministries of happiness. This is corroborated somewhat by the relative success of federal systems supporting significant local and state governments.

\section{Tolerance of Constraint}

Initially in this research, it appeared that tolerance of constraint could be plotted on an indifference curve versus relative to its probable positive benefits. As long as the perceived benefits of constraint increased, so too would tolerance for constraint. However, this only applies linearly in a perfectly homogenous society. The greater the diversity there is, the greater the likelihood exists that a particular constraint is extremely distasteful to some faction. In an Amish community, gun-control and mandatory antismog devices on all engines meet little objection. In Jerusalem, a law forbidding Moslem and Christian religious observances would meet great resistance. In an increasingly diverse social group, constraint on more than the nearly universal concerns (such as violent crimes, armed coercion, theft and others) risks impairing what some cleavages consider necessary to their livelihood. 
The communitarian ideal, seems to be vulnerable to over-broad statements of morality. The difficulty is one of applying an average morality to all members heedless of their particular ethics and environment. As William R. Lund notes:

Virtue talk has a strong tendency to fall in to 'maximizing' mode, and to subordinate individual choosers to particular choices judged likely to increase the amount of flourishing in the world. Simply put, in analyzing the practical implications of communitarian equality, we find all of the dangers, and few responses to the various criticisms of, state-enforced perfectionism. (597)

Again, Martensson's conclusion that no theory of rationality can be proved to be most rational, and that therefore individuals should make their own moral choices, holds.

\section{Constraint versus Efficiency}

Constraint has costs. The exertion of constraining requires resources and the constraining itself denies choices, which is also a sacrifice. A system that is required to exert more control over individuals than competing systems can be said to be inelegant for necessitating the additional expenditure of resources toward similar ends. And, the control is likely viewed by the rational actors with the system as a burden (a cost).

Efficiency is typically improved with economies of scale and standardization.

Taken to its logical extreme, this implies creating a society of clones with one desire and one acceptable means of fulfillment. Tending towards that extreme involves funneling diverse people through just a few gates. Social systems may constrain individuals from taking options the system does not want to accommodate. 
An ideal system would expend no resources on constraint and yield $100 \%$ production with its efforts. The actors would not be hindered by the system, only leveraged by it. To obtain that extreme, actors would have to agree the system was the best means of achieving each of their individual priorities in succession. To approach that ideal, the system would have to limit the areas it enters and the costs it exacts.

Swedish author Karin Boye's 1940 work Kallocain puts it romantically: ". . . like Shoppenhauer, views the most essential part of the mind as the unconscious force of life. There is little conflict between true individualism and true human compassion, it says, but a strong conflict between enforced social behavior and the true self" (Martensson 489). A best system would expend minimal resources on constraint.

\section{Optimums}

Within the course of this work and the considerations and conclusions it offers, a number of optimums suggest themselves as rules of thumb for the analyst. These optimums can be summarized as follows:

1. Ideally, $100 \%$ of aggregate resources would be spent creating positive benefits rather than suppressing negative occurrences.

2. Ideally, a system facilitates actors aggregating into whatever interest groups (cleavages) they prefer to bring pressure upon the system to service their needs.

3. Ideally, a system is amenable to modification as needs change. 
4. Ideally, system administrators are sufficiently dependent on the common actors for their own needs (which presumably include the benefits of being system administrator) so that they are responsive to these actors.

5. Ideally, internal pressures to serve one's needs are counter balanced by external pressures to facilitate (or at least not inhibit) others' serving their needs.

\section{Generalizations}

This thesis has suggested a number of generalizations concerning factors that may cause systems to veer away from optimums. These can be summarized as follows:

1. If equilibrium is lost, some actors have their needs met less well and as a result, they will contribute less to the system.

2. If actors receive without correlation to what they produce, then their production will likely drop.

3. If actors contribute without correlation to what they receive, then what they are given will likely drop (and, eventually, what they produce will also likely drop as a result).

4. If actors receive in proportion to what they produce (assuming a reasonable return), then their produce will approach pareto-optimality.

5. Actors cede maximum resources when they are content with their cost/benefit ratio.

6. The system is most effective with large amount of resources. 
7. The system obtains maximum allegiance by convincing actors it is the best means to attain their ends.

8. The system receives maximum resources by convincing actors they must cede resources to yield benefits.

9. The system yields maximum service when it is convinced it must produce services to receive resources.

10. The system adapts services when it is convinced it must adapt in order to continue receiving resources.

11. A bad system incentivises people to adapt into someone that produces less of value for themselves and consume more produced by others.

\section{What is Suggested About Healthy Systems?}

Systems that forbid many things may expend excessive amounts of resources on constraint or compelling compliance. A pliable, "grow-able" system is supported on the margin; the more it is used, the more it is supported. Therefore, if it were in everybody's interest to use it, it would be equally in enough people's interest to support it.

This can be achieved by pay as you go access fees, or by raising access cost at the point which diminishing returns or escalating costs occurs. Ultimately, a system can only have balance and equilibrium under these conditions: power is distributed, individuals contribute pending acknowledgment of their desires, the system is sometimes responsive 
to their concerns, taxes and restrictions are widely accepted as legitimate, individuals are incentivised to succeed, and the system shares in their successes. 


\section{Chapter Sixteen}

This chapter examines the advantages and disadvantages of our three analytical approaches to assessing reform proposals, and makes recommendations for their optimal usage.

Testing by abnegation has some distinct advantages. It is reasonably quick. It directs attention to specific criteria and, after several negatives are found gives a general idea of the viability of the proposed system. Testing by abnegation filters out extremely weak proposals well. It illuminates where a plan needs improvement. It finds faults.

Testing by abnegation has some disadvantages, however. Since it does not measure what a plan does well, it gives no measurement of the strengths of a plan. Although its categories are fixed, the test is still highly subjective. Analysts must discriminate between minor and major occurrences of the categorized flaws. Testing by abnegation does educate, but primarily in an unconstructive manner. It allows comparison of social systems, but only on the basis of the negatives of each social system.

Testing by affirmation has some advantages. This test establishes indicators for success. It measures plans by the standard of how constructive they are and allows comparison of plans' strengths. Highlighting advantageous traits in an assessment 
encourages optimization, balance and thoroughness. Its framework enhances comprehension of the factors that strengthen a social system.

Testing by affirmation has some disadvantages. A more thorough review of the proposal is required. It is still a highly subjective test. It requires many assumptions about details of the plan that may not have been disclosed. It requires analysts to estimate which strengths can least well be done without.

Testing with ad hoc analysis has advantages. It tends to find the most compelling strengths and weaknesses first. It avoids biases associated with formulaic analysis. It doesn't attempt to force new insights into a preexisting category. It need not be "learned", and there is no distortion from its incomplete application. It is as fast or as slow as desired and can still give useful answers.

It fits in well when the assessment of the reform proposal is a subset of a larger work. Biographers of reformers, for example, would be interested in what the proposed reforms revealed about their authors. A more structured analysis might distract from the flow of the character study. Ad hoc analysis is free to mention only what is salient to the reviewer's interests.

Testing with ad hoc analysis has disadvantages. It may be haphazard. It is more difficult for it to be thorough, balanced, and retain perspective. It is more difficult to use in comparisons of disparate systems, because the noticeable traits of each may not be readily comparable. Testing with ad hoc analysis may not yield a useful answer even after a lengthy consideration. 
What stands out about each approach? Ad hoc analysis can still give a correct general answer: "Yes this planned social system bears looking into"; "No, this planned social system won't work". Abnegation can thin a large field of plans quickly, although it may miss useful modules that could be incorporated successfully into a different proposal. Affirmation is best at comparing finalists based on merit.

All three approaches are probably advantageous at times. We recommend a mixed usage depending upon the context. For any significant proposed change, we recommend using all three approaches.

If an analyst were looking for a single approach that hybridized all of the above, he or she might use the following outline of questions to begin an exploration. Notable elements of each analytical approach could be prospected for simultaneously:

What is an ideal measuring tool for reform proposals?

A. Weigh costs and benefits of produce

B. Gauge certainty of benefits

1. Reliability of proposed system

2. Stability of proposed system

3. Incorruptibility of proposed system

4. Tolerance for non-compliance

5. Adaptability/responsiveness for correction

6. Feasibility of transition

C. Weigh transition costs 
1. What percent must cooperate for success?

2. Is there time to ascend the learning curve?

D. Compare to desires of populace

1. Is cost proportional to desire?

2. Is benefit proportional to desire?

3. Is pursuit of other significant desires inhibited?

4. Is populace committed to social system?

Realize there is no apparent calculus of social activity

A. Desires are provisional

B. Supply and demand changes cost

1. People change pursuits depending what others pursue

a. Feedback loop can be multiplicative

b. Feedback loop can be infinitely regressive

2. With different costs, people adjust pursuits

C. Data are subjective \& defy quantification

Would-be reformers face challenges

A. Reform proposals always contend with limited information

1. The disenfranchised do not report

2. Legislators may understand proposal differently

3. It is unknown how future events would affect the proposed system 
B. Reform proposals should at the minimum be reasonably certain of being able to work well.

1. With what can be projected

2. With what is known

3. With cleavages that report

\section{In Conclusion...}

This thesis suggests applying three analytical approaches to existing social systems for comparison to each other, and to proposals of systemic reform. Suggested advances of this line of reasoning include comparing socialist, capitalist and marxist economies; comparing feudalism, totalitarianism and democracy; comparing the empires of Persia, Greece and Rome in their ascendancy; comparing feminist, fascist and technocratic utopias; comparing various forms of local government; or comparing the organizational philosophy of businesses, universities and bureaucracies.

This research may be used to advance the fields of comparative politics, political theory, and cybernetic systems. While there is much room to refine definitions and remove some subjectivity from its application, these three approaches will always necessitate some personal estimation of conditions and intensities. The insights of the analyst will augment or diminish the effectiveness of each approach.

This thesis may assist decision-makers. While most proposals to reform social systems are far from utopian, the opportunity exists with each reform to make mistakes 
similar to those of an arch-typal utopist. Whether those actors with discretion to act on behalf of their fellows are conservative or liberal, progressive or traditional, individualist or collectivist, optimist or pessimist, romantic or pragmatist; they must all contend with the limitations of their perspective and the pitfalls of the planning process. This series of approaches may afford such planners the opportunity for increased self-awareness and additional insight into their own thought processes. To that end, this work is not ended, but just begun. 
Selected Bibliography

Bellamy, Edward. Looking Backward 2000-1887. 1887. New York: Random House. 1951.

Beecher, Jonathan. Charles Fourier, the Visionary and His World. Berkeley: UC Press, 1986.

Campanella, Tommaso. The City of the Sun. Trans. T.W. Halliday. Included in PeaceableKingdoms: An Anthology of Utopian Writings. Ed. Robert L. Chianese. New York: Harcourt Brace Jovanovich, Inc., 1971, 3-41.

Coon, Dennis. Essentials of Psychology. Fourth Edition, St. Paul MN: West Publishing Co., 1988.

Dahrendorf, Ralf. Essays in the Theory of Society. Stanford: Stanford U. Press, 1968.

Dawson, Doyne. Cities of the Gods. New York: Oxford University Press, 1992.

Fourier, Francois Marie Charles. Theory of the Function of the Human Passions. Comp. Trans. and Ed. Albert Brisbane. New York: Miller, Orton, \& Mulligan, 1856.

Gardner, Hugh. The Children of Prosperity, 13 Modern Communes. New York: St. Martin's Press, 1978.

Hansot, Elisabeth. Perfection and Progress: Two Modes of Utopian Thought. Cambrdige MA: MIT Press, 1974.

Huxley, Julian. "A Planetary Utopia", Unesco Courier. Feb. 1991: 41.

Kateb, George., ed. "Out of Utopia: Toward a reorientation of sociological analysis" Utopia. New York: Atherton Press, 1971.

Kumar, Krishnan. Utopia \& Anti-utopia in Modern Times. London: Basil Blackwell Inc., 1987.

Leclerc, Gilbert. "Non-Stop Learning", Unesco Courier. Feb. 1991: 21-23. 
LeWarne, Charles P. Utopias on Puget Sound, 1885-1915. Seattle WAS: University of Washington Press, $19 ? 5$.

Lund, William R. "Communitarian Politiss and the Problem of Equality" Political Research Quarterly. Sec. 1993 V46́-3: 577-.539.

Manuel, Frank E., ed. Utopias \& Utopian Thought. Boston MA: Houghton Mifflin Co., 1965.

Manuel, Frank E., and Fritzie P. Manuel. Utopian Thought in the Western World. Cambridge MA: Belknap Press of Harvard University, 1979.

Martensson, Bertil. "The Paradoxes of Utopia", Philosophy of the Social Sciences. Dec. 1991. V21-4: 476-514.

Molnar, Thomas. Utopia. The Perennial Heresy. New York: Sheed and Ward, 1967.

Morris, William. News From Nowhere. London: Rutledge \& Kegan Paul, 1970.

Muncy, Raymond. "Sex and Marriage in Utopia" Society. Jan./Feb. 1988: 54-61.

Negley, Glenn, and J. Max Patrick. The Quest for Utopia. New York: H. Schumann, 1952.

Pfaelzer, Jean. The Utopian Novel in American 1886-1896. Pittsburgh: U. Pittsburgh Press, 1984.

Ray, Amitava. Political Utopianism: Some Philosophical Problems. Calcutta: Temple Press, 1979.

Roemer, Kenneth. "Appendix to Build Your Own Utopia". Houston: Self Published, 1981.

Sargent, Lyman Tower. British and American Utopian Literature, 1516-1985. New York: Garland Publishing, 1985.

Stephens, Anthony. "The Sun State and its Shadow. . " Utopias. Melbourne: Oxford University Press, 1987. 
Task Force on National Health Care Reform. Clinton Health Security Act. Washington, 1994.

Veatch, Henry. Order. Freedom and the Polity: Critical Essays on the Open. Society. Ed. George W. Carey. Lanham MD: University Press of America, 1986.

Warren, F.M. Ten Frenchmen of the Nineteenth Century. Chautauqau NY: The Chatauqua Press, 1904.

Wells, H. G. A Modern Utopia. 1905. Lincoln: U. Nebraska Press, 1967. 